Prepared for the U.S. Department of Energy

under Contract DE-AC05-76RL01830

\title{
Integrated Assessment Plan Template and Operational Demonstration for SPIDERS Phase 2: Fort Carson
}

\section{JL Barr}

FK Tuffner

MD Hadley

SJ Kreyling

KP Schneider

September 2013

Pacific Northwest NATIONAL LABORATORY

Proudly Operated by Battelle Since 1965 


\title{
DISCLAIMER
}

This report was prepared as an account of work sponsored by an agency of the United States Government. Neither the United States Government nor any agency thereof, nor Battelle Memorial Institute, nor any of their employees, makes any warranty, express or implied, or assumes any legal liability or responsibility for the accuracy, completeness, or usefulness of any information, apparatus, product, or process disclosed, or represents that its use would not infringe privately owned rights. Reference herein to any specific commercial product, process, or service by trade name, trademark, manufacturer, or otherwise does not necessarily constitute or imply its endorsement, recommendation, or favoring by the United States Government or any agency thereof, or Battelle Memorial Institute. The views and opinions of authors expressed herein do not necessarily state or reflect those of the United States Government or any agency thereof.

\author{
PACIFIC NORTHWEST NATIONAL LABORATORY \\ operated by \\ BATTELLE \\ for the \\ UNITED STATES DEPARTMENT OF ENERGY \\ under Contract DE-AC05-76RL01830
}

Printed in the United States of America
Available to DOE and DOE contractors from the Office of Scientific and Technical Information,
P.O. Box 62, Oak Ridge, TN 37831-0062;
ph: (865) 576-8401
fax: $(865)$ 576-5728
email: reports@adonis.osti.gov

\begin{abstract}
Available to the public from the National Technical Information Service, U.S. Department of Commerce, 5285 Port Royal Rd., Springfield, VA 22161 ph: (800) 553-6847 fax: $(703) 605-6900$ email: orders@ntis.fedworld.gov online ordering: http://www.ntis.gov/ordering.htm
\end{abstract}

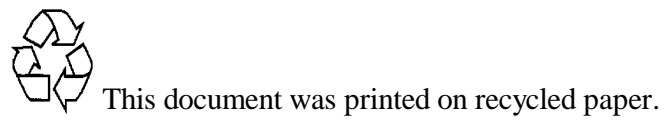




\title{
Integrated Assessment Plan Template and Operational Demonstration for SPIDERS Phase 2: Fort Carson
}

\author{
JL Barr \\ MD Hadley \\ SJ Kreyling \\ KP Schneider
}

FK Tuffner

September 2013

Prepared for

the U.S. Department of Energy

under Contract DE-AC05-76RL01830

Pacific Northwest National Laboratory

Richland, Washington 99352 


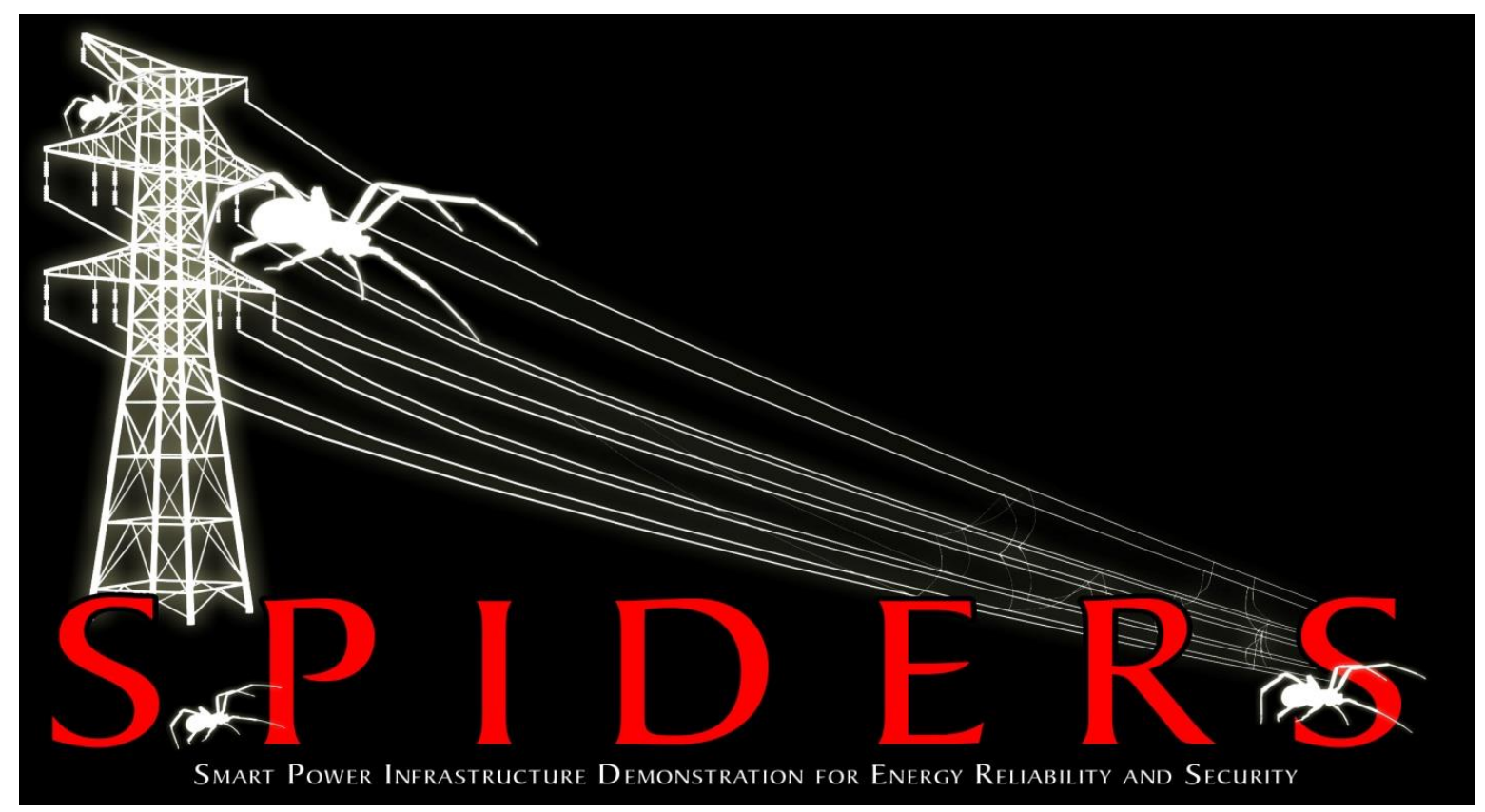

\section{Integrated Assessment}

\section{Phase 2 Operational Demonstration}

\section{October 2013}
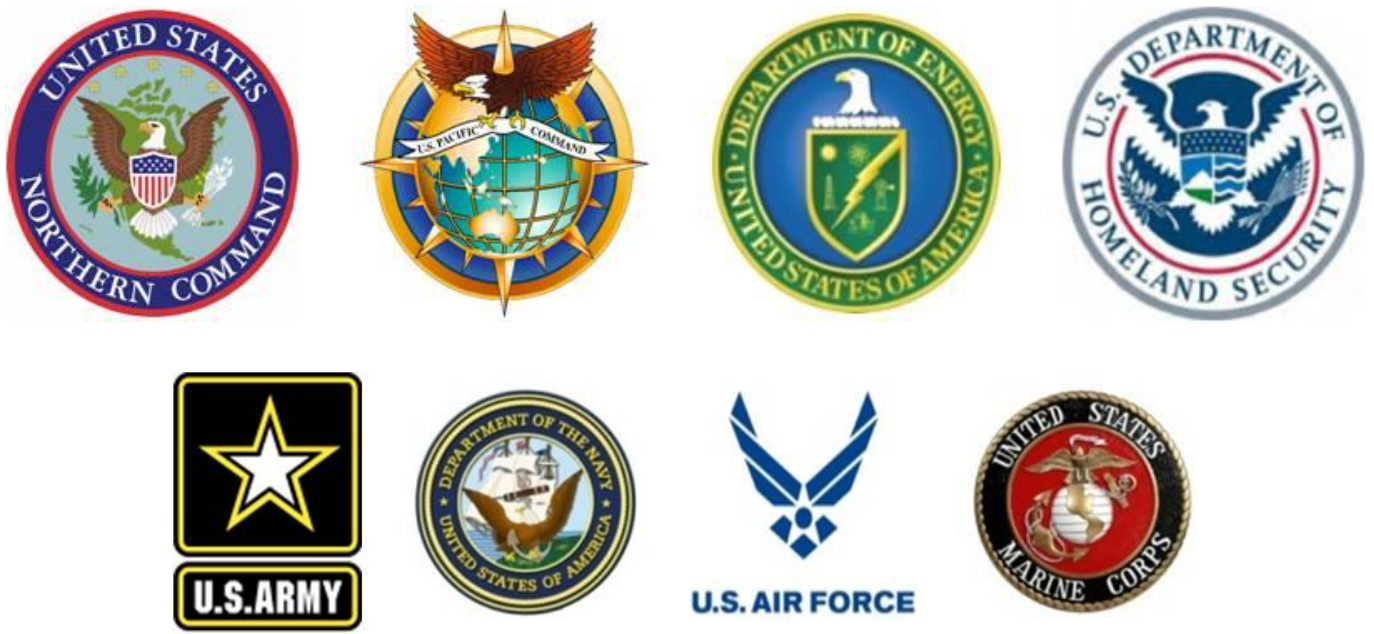

U.S. AIR FORCE
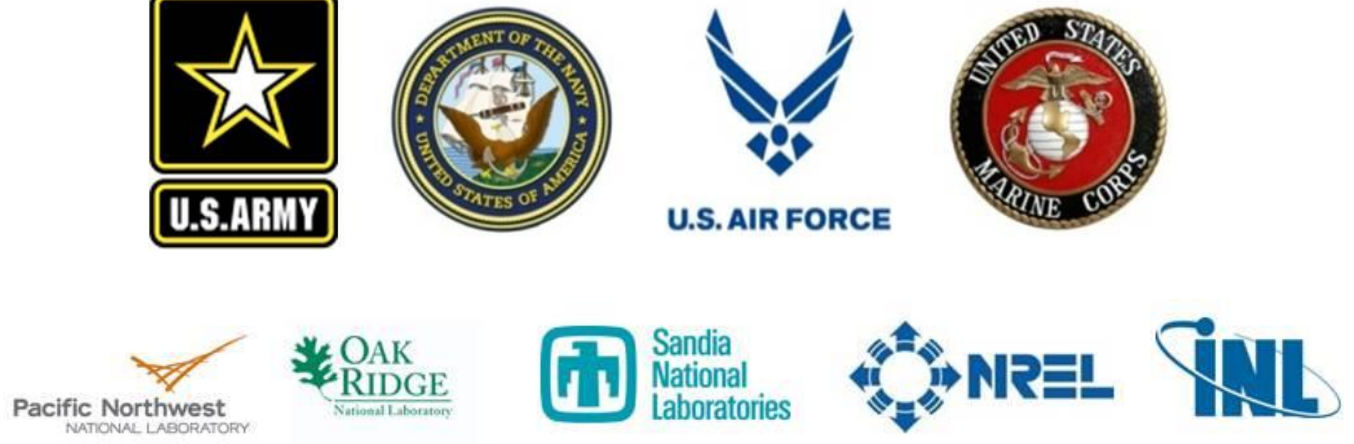


\section{Table of Contents}

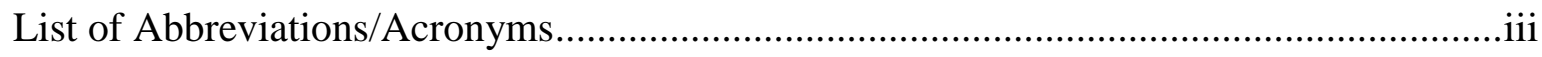

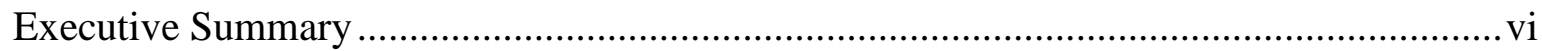

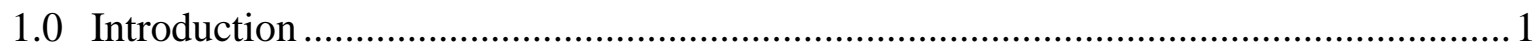

2.0 Operational Demonstration Execution Plan (ODEP) ............................................... 3

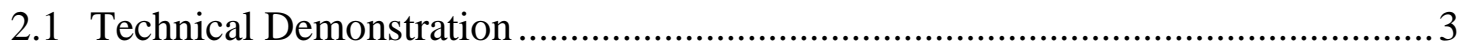

2.2 Operational Demonstration ..................................................................... 3

3.0 Evaluation Metrics (MOEs and MOPs) ................................................................ 7

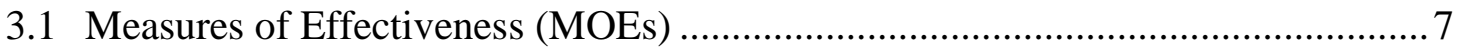

3.2 Measures of Performance (MOPs) .................................................................... 8



5.0 Operational Assessment Execution Plan (OAEP) .................................................. 24

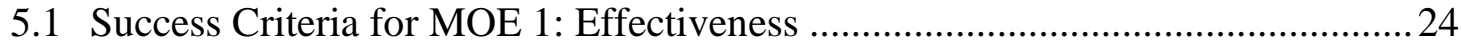

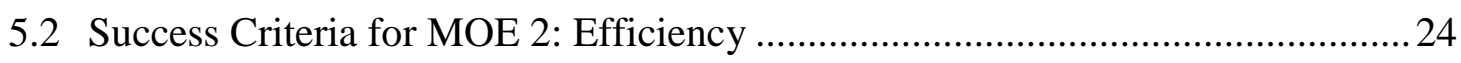

5.3 Success Criteria for MOE 3: Renewables Integration .....................................24



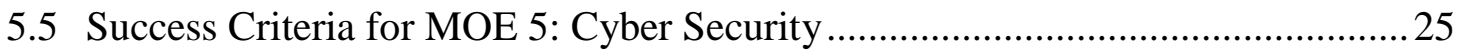

5.6 Mapping Measurement Points to MOPs ......................................................... 25

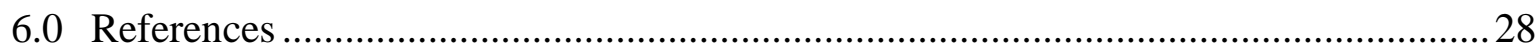

Appendix A: SPIDERS Measures of Effectiveness (MOEs) .......................................29

Appendix B: Phase 2 OD Operational Procedure and Responses to Abnormal Conditions70 


\section{Table of Tables}

Table 2.1 SPIDERS Facilities at Fort Carson .............................................................. 4

Table 3.1: MOEs for Fort Carson .............................................................................. 7

Table 3.2: MOPs for MOE 1................................................................................... 9



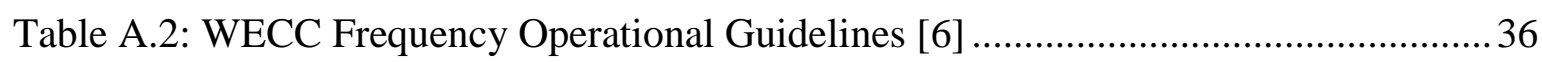

Table A.3: Caterpillar 1.6 MW CO 2 Diesel Generator Emission Values ......................... 41

Table A.4: Caterpillar 1.6 MW NOx Diesel Generator Emission Values ........................ 44

Table A.5: Caterpillar 1.6 MW SOx Diesel Generator Emission Values......................... 47

Table A.6: Caterpillar 1.6 MW PM-10 Diesel Generator Emission Values........................50 


\section{List of Abbreviations/Acronyms}

This section contains a list of all abbreviations/acronyms used in this document.

\begin{tabular}{|c|c|}
\hline $\mathrm{B} \& \mathrm{M}$ & Burns \& McDonnell \\
\hline CAIDI & Customer Average Interruption Duration Index \\
\hline $\mathrm{CP}$ & Casualty Procedure \\
\hline CSET & Cyber Security Evaluation Tool \\
\hline CSU & Colorado Springs Utilities \\
\hline $\mathrm{CO}_{2}$ & Carbon Dioxide \\
\hline CONOPS & Concept of Operations \\
\hline COTS & Commercial off the Shelf \\
\hline $\mathrm{CP}$ & Casualty Procedure \\
\hline CVR & Conservation Voltage Reduction \\
\hline DG & Diesel generator \\
\hline DIACAP & DoD Information Assurance Certification and Accreditation Process \\
\hline DNS & Domain Name System \\
\hline DoD & Department of Defense \\
\hline DOE & Department of Energy \\
\hline DPW & Department of Public Works \\
\hline EMS & Energy Management System \\
\hline ESM & Energy Surety Microgrids \\
\hline EVSE & Electric Vehicle Supply Equipment \\
\hline gal & Gallon \\
\hline FEMP & Federal Energy Management Program \\
\hline GUI & Graphical User Interface \\
\hline $\mathrm{Hz}$ & Hertz \\
\hline HMI & Human Machine Interface \\
\hline IAP & Integrated Assessment Plan \\
\hline ID & Implementation Directive \\
\hline IMT & Integrated Management Team \\
\hline IPC & Integrated Power Controller \\
\hline IPERC & Intelligent Power \& Energy Research Corporation \\
\hline IT & Information Technology \\
\hline Lbm. & Pound (mass) \\
\hline JCTD & Joint Capability Test Demonstration \\
\hline kVAR & Kilovolt amp reactive \\
\hline $\mathrm{kVARh}$ & Kilovolt amp reactive hour \\
\hline $\mathrm{kW}$ & Kilowatt \\
\hline $\mathrm{kWh}$ & Kilowatt hour \\
\hline MAIFI & Momentary Average Interruption Frequency Index \\
\hline MD & Microgrid Discretionary \\
\hline
\end{tabular}




\begin{tabular}{|c|c|}
\hline ME & Microgrid Essential \\
\hline MOE & Measure of Effectiveness \\
\hline MOP & Measure of Performance \\
\hline MS & Microgrid Supported \\
\hline NIST & National Institute of Standards and Technology \\
\hline NORTHCOM & Northern Command \\
\hline NOx & Nitrogen Oxides \\
\hline NTP & Network Time Protocol \\
\hline OAEP & Operational Assessment Execution Plan \\
\hline ODEP & Operational Demonstration Execution Plan \\
\hline $\mathrm{OE}$ & Oversight Executive \\
\hline OD & Operational Demonstration \\
\hline $\mathrm{OM}$ & Operational Manager \\
\hline $\mathrm{OP}$ & Operational Procedure \\
\hline OS & Operating System \\
\hline OTA & Operational Test Authority \\
\hline OTE & Operational Test and Evaluation \\
\hline PACOM & Pacific Command \\
\hline pf & Power Factor \\
\hline PCC & Point of Common Coupling \\
\hline PM-10 & Particulate Matter \\
\hline PNNL & Pacific Northwest National Laboratory \\
\hline PRA & Probabilistic Risk Assessment \\
\hline PV & Photo Voltaic \\
\hline RMS & Root Mean Squared \\
\hline SAIDI & System Average interruption Duration Index \\
\hline SAIFI & System Average interruption Frequency Index \\
\hline SCADA & Supervisory Control And Data Acquisition \\
\hline SOP & Standard operating Procedure \\
\hline SOx & Sulfur Oxides \\
\hline $\mathrm{SO}_{2}$ & Sulfur Dioxide \\
\hline SP & Special Publication \\
\hline SPIDERS & Smart Power Infrastructure Demonstration for Energy Reliability and Security \\
\hline $\mathrm{TD}$ & Technical Demonstration \\
\hline THD & Total Harmonic Distortion \\
\hline TM & Technical Manager \\
\hline TTP & Tactics Techniques and Procedures \\
\hline UAR & Utility Assessment Report \\
\hline UPS & Uninterruptible Power Supply \\
\hline UV & Ultraviolet \\
\hline $\mathrm{V}$ & Volt \\
\hline $\mathrm{V} 2 \mathrm{G}$ & Vehicle-to-Grid \\
\hline
\end{tabular}




$\begin{array}{ll}\text { Vrms } & \text { Voltage root-mean-square } \\ \text { VSE } & \text { Virtual Secure Enclave } \\ \text { VVO } & \text { Volt-Var Optimization } \\ \text { WTG } & \text { Wind Turbine Generator } \\ \text { WWTP } & \text { Waste Water Treatment Plant } \\ \text { XFMR } & \text { Transformer } \\ \text { XM } & \text { Transition Manager }\end{array}$




\section{Executive Summary}

This document contains the Integrated Assessment Plan (IAP) for the Phase 2 Operational Demonstration (OD) of the Smart Power Infrastructure Demonstration for Energy Reliability and Security (SPIDERS) Joint Capability Technology Demonstration (JCTD) project. SPIDERS will be conducted over a three year period with Phase 2 being conducted at Fort Carson, Colorado. This document includes the Operational Demonstration Execution Plan (ODEP) and the Operational Assessment Execution Plan (OAEP), as approved by the Operational Manager (OM) and the Integrated Management Team (IMT). The ODEP describes the process by which the OD is conducted and the OAEP describes the process by which the data collected from the OD is processed. The execution of the OD, in accordance with the ODEP and the subsequent execution of the OAEP, will generate the necessary data for the Quick Look Report (QLR) and the Utility Assessment Report (UAR). This reports will assess the ability of the SPIDERS JCTD to meet the four critical requirements listed in the Implementation Directive (ID) for the Phase 2 demonstration. 


\subsection{Introduction}

The Implementation Directive (ID) states that the objectives of the Smart Power Infrastructure Demonstration for Energy Reliability and Security (SPIDERS) Joint Capability Technology Demonstration (JCTD) is to demonstrate a cyber-secure microgrid architecture with the ability to maintain operational surety through secure, reliable, and resilient electric power generation and distribution. There are four critical requirements listed in the ID as being necessary to demonstrate enhanced power surety for national security:

1) Protect task essential assets from loss of power due to cyber-attack.

2) Integrate renewables and other distributed energy generation concepts to power task essential assets in times of emergency.

3) Sustain essential operations during prolonged power outages.

4) Manage installation electrical power and consumption efficiency, to reduce petroleum demand, carbon "bootprint," and cost.

SPIDERS is a three phase project; this document will focus on the second phase. In the second phase of the SPIDERS JCTD the primary goals are to show the ability to properly operate a multi-feeder microgrid in an islanded mode in the presence of significant renewable resources. This requires the system to maintain voltage and frequency control in a cyber-secure environment. Only a small portion of the Fort Carson electrical system is augmented by SPIDERS, and the SPIDERS enabled facilities along the Specker Corridor (Table 2.1) are treated as the essential loads. Under normal operating conditions, these facilities are supplied by the Colorado Springs Utility (CSU) system through the O'Connell, Minick and Titus substations. Utility power is available to all essential and non-essential loads consistent with Fort Carson Standard Operating Procedures (SOPs). When the SPIDERS system is islanded, the essential load will be served by a microgrid composed of portions of multiple distribution feeders, diesel generators, solar Photovoltaic (PV), and energy storage in the form of an Electric Vehicles (EVs). It is the ability of SPIDERS to effectively operate this microgrid, in a cyber-secure environment, that is being evaluated.

The evaluation of the effectiveness of the second phase of SPIDERS will be determined by conducting a 80 hour Operational Demonstration (OD). The OD is scheduled to be conducted October $21^{\text {st }}$ through the $24^{\text {th }}$ of 2013 . The actual test will potentially take longer than 80 hours because of the time required to separate from the utility at the beginning, and the time required to reconnect at the end. This document details the process by which the OD is executed, the data is analyzed, and how the results are evaluated with respect to the four critical requirements of the ID. This document is organized as follows: Section 1 details the Operational Demonstration Execution Plan (ODEP) and Section 2 introduces the evaluation metrics; Section 3 is an overview of the measurements that are available and Section 4 is the Operational Assessment Execution Plan (OAEP); Appendix A details the Measures of Effectiveness (MOEs) and 
Measures of Performance (MOPs); and finally, Appendix B contains the operational procedure for the $\mathrm{OD}$, including responses to abnormal conditions. 


\subsection{Operational Demonstration Execution Plan (ODEP)}

The ODEP details the procedures for properly conducting the OD. The purpose of the OD is to collect the data necessary to determine SPIDERS operational effectiveness as outlined in the Implementation Directive (ID). The data collected in the OD, per the ODEP, is then post processed in the OAEP.

\subsection{Technical Demonstration}

The TD will be completed in stages prior to the OD. The TD will be conducted by the system integrator, Burns \& McDonnell (B\&M), and the Fort Carson facilities staff. The OTA will participate in the capacity of an observer, but no data will be collected other than for the purposes of determining baseline parameters. Data may also be collected during the TD to highlight potential future modes of operation. The TD will also be utilized by the OTA to ensure that the ODEP is properly aligned with the ground truth of SPIDERS operation and installation and the ODEP can be refined if necessary.

\subsection{Operational Demonstration}

The OD is divided into four stages, three fully operational stages and a cyber stage consisting of both operational and non-operational components. This non-operational stage is an evaluation of the SPIDERS cyber systems through code review, bench testing, and Red Team activities. The operational stages cover the separation of the SPIDERS system from the Colorado Springs Utility (CSU) system, independent islanded operation, and reconnection with the CSU system.

The OD is performed over a 80 hour period. Initially, all SPIDERS supported facilities (Table 2.1) are in a normal configuration with power supplied from the three separate circuits from three separate substations interconnected by normally opened switches. Circuit 1 originates from the O'Connell substation, circuit 10 from the Titus substation, and circuit 24 from the Minick substation. The circuits are interconnected via manual switches that allow power to be routed from different substations. The SPIDERS control system can be manually instructed to shift to an islanded mode with power supplied by local generation. The ability of SPIDERS to successfully separate from the CSU system and transfer to an islanded mode is the Stage 1 evaluation. Once a stable island is formed, the Stage 2 evaluation will commence. This is a 80 hour evaluation that will focus on the ability of SPIDERS to effectively manage the integration of variable output generation resources in order to reduce the consumption of diesel fuel. This is a measure of the system's ability to increase the duration during which essential operations can be maintained. Stage 3 will be an evaluation of the ability of SPIDERS to successfully reconnect with the CSU system. At the end of the Stage 3 evaluation, all SPIDERS facilities along the Specker Corridor will be connected to the normal power supply from the CSU system as previously detailed. 
Table 2.1 SPIDERS Facilities at Fort Carson

\begin{tabular}{|l|l|}
\hline \multicolumn{1}{|c|}{ Description } & Generator Incorporated \\
\hline 4ID Division HQ & $1,250 \mathrm{~kW}$ \\
\hline Headquarters Battalion & \\
\hline Installation Processing Center & \\
\hline Main Library & $1,000 \mathrm{~kW}$ \\
\hline $\begin{array}{l}\text { Network Enterprise Center Data } \\
\text { Center }\end{array}$ & $900 \mathrm{~kW}$ \\
\hline Network Enterprise Center Annex & \\
\hline Network Communications Center & \\
\hline
\end{tabular}

The following subsections will describe the various stages of the OD in detail.

\subsubsection{Stage 0: Cyber Evaluation}

Multiple cyber assessment activities will occur during Phase 2 of the SPIDERS project. Ensuring a thorough and complete assessment of systems, components, and human factors related to SPIDERS' cyber security requires that the Operational Test Authority (OTA) have access to the spaces, systems, and personnel associated with SPIDERS operation. The first assessment activity will evaluate the design and implementation of the Fort Carson microgrid using the Cyber Security Evaluation Tool (CSET) application. Compliance with the DoD 8500.2 and NIST SP 800-82 will be evaluated. The Phase 2 CSET evaluation effort requires input from multiple data sources:

1) The Burns \& McDonnell 100\% design,

2) The NORTHCOM DoD Information Assurance Certification and Accreditation Process (DIACAP) documentation,

3) Interviews with Fort Carson microgrid operators,

4) Interviews with Burns \& McDonnell and IPERC staff, and

5) Onsite evaluation of the Fort Carson microgrid operational demonstration environment.

The timing of the CSET evaluation will coincide with the Operational Demonstration (OD).

Pacific Northwest National Laboratory (PNNL) staff will evaluate IPERC software using multiple static code analysis tools, analyze the findings, and recommend mitigation strategies during the second cyber security assessment activity. The process of evaluating source code provides an opportunity to improve cyber security by identifying security concerns such as memory leaks, lack of bounds checking, or the use of insecure methods before an exploit is created by adversaries. This second assessment activity will be conducted during or before the OD and will be conducted at the IPERC facility in Boulder, Colorado. 
The Red Team assessments are the third assessment activity. Lessons learned from the CSET evaluation will be provided to the Red Team for the live portion of the cyber evaluation. It is expected that the rules of engagement will constrain the testing that will be allowed on the operational system to prevent unintended consequences, such as equipment damage or leaving devices in an unknown operational state. PNNL will both observe Red Team activities and perform passive analysis on the environment by capturing network traffic, analyzing the traffic to evaluate both performance and resiliency, and ensuring that only expected communication is present on the operational network. Tests that cannot be conducted during the live tests will be documented and included in a future vulnerability assessment evaluation.

The benefits of this three-part cyber assessment approach include:

- The ability to verify CSET responses by interviewing staff and monitoring network communications,

- The ability to evaluate components without causing harm to the operational environment,

- Providing IPERC the opportunity to mitigate any vulnerabilities identified in their source code for future projects, and

- An opportunity to provide information from one testing activity to another, modeling iterative processes used in cyber attacks by intelligent adversaries.

The results of CSET and static code analysis activities will be included in the final Utility Assessment Report (UAR). If the Red Team activities are completed prior December $15^{\text {th }}, 2013$ they will also be integrated into the Stage 0 portion of the UAR, otherwise that analysis will be included in Phase 3 documentation.

\subsubsection{Stage 1: Separation from CSU System}

This stage begins with the SPIDERS facilities being in a normal configuration with power supplied from the CSU system. The solar PV and EVSEs may or may not be in operation, but the diesel generators are not in operation. The first stage commences when the manual command to transition to independent islanded operations is given through the SPIDERS HMI. This stage is completed as soon as interconnected operations are terminated, and a stable operating island is formed. A stable operating island is defined as operations independent of the CSU system with power provided by a facility diesel generator(s) and solar PV, possibly with the EVSEs and EVs included. Both voltage and frequency must be stable about nominal operating values.

\subsubsection{Stage 2: Islanded Operations}

This stage begins after the successful separation from the CSU system and the formation of a stable island. The ability of SPIDERS to manage the operation of variable output renewable resources and to reduce primary fuel consumption while supplying the essential load is the primary focus of this stage. This stage is completed when the manual command to reconnect to the CSU system is given. 


\subsubsection{Stage 3: Reconnecting with the CSU System}

This stage begins with the completion of the 80 hour test period of Stage 2, with the system still operating as a stable island, and the command to reconnect to the utility system has been given. This stage will examine the ability of SPIDERS to seamlessly interconnect with CSU system. For further details on mechanics of the stages discussed here the reader is encouraged to review Section 5.3.1.1, Sequence of Operations, in the SPIDERS: Fort Carson Concept of Operations document. 


\subsection{Evaluation Metrics (MOEs and MOPs)}

In order to determine the effectiveness of SPIDERS, it is necessary to define the metrics that will be used for evaluation. These metrics will be used to determine the ability of SPIDERS to meet the critical requirements set forth in the ID. For the purposes of this JCTD, the highest level metrics used for evaluation are referred to as Measures of Effectiveness (MOEs). MOEs are operational evaluations of SPIDERS' ability to meet the ID requirements. The failure of any individual MOE will indicate an inability to meet all critical requirements of the ID. In order for the MOEs to be properly supported they must be based on measurements of the operational system; these are referred to as Measures of Performance (MOPs). MOPs are the individual measurements that are made on the SPIDERS system, such as generator output in kilowatts or the binary status of a switch. It is the quantitative metrics associated with the majority of the MOPs that forms the basis for a grounded qualitative evaluation of the MOEs. The following sections briefly describe the various MOEs and MOPs that will be used for the Phase 2 evaluation of SPIDERS at Fort Carson. Appendix A gives more detailed information on the individual MOPs and how they are measured and/or calculated.

\subsection{Measures of Effectiveness (MOEs)}

MOEs are used as the first link between the conceptual statements of the ID and the evaluated operational parameters of the OD. In order for the OD to be successful, it must be shown that SPIDERS successfully supported each of the four critical requirements of ID, thus all of the MOEs must receive a passing status. 3.1 shows the mapping between the various MOEs and the ID requirements.

Table 3.1: MOEs for Fort Carson

\begin{tabular}{|l|l|c|}
\hline \multicolumn{2}{|c|}{ MOEs } & $\begin{array}{c}\text { ID Requirement } \\
\text { Supported }\end{array}$ \\
\hline 1 & Effectiveness & \\
\hline 1.1 & Increased runtime & \multirow{2}{*}{3,4} \\
\hline 1.2 & Additional load & \\
\hline 1.3 & Reliability & \\
\hline 1.4 & Power quality & \multirow{2}{*}{2,4} \\
\hline 2 & Efficiency & \\
\hline 2.1 & System & \multirow{2}{*}{2,4} \\
\hline 2.2 & End use & \\
\hline 3 & Renewables Integration & \multirow{2}{*}{$1,2,3,4$} \\
\hline 3.1 & PV penetration level & \\
\hline 4 & Suitability & \\
\hline 4.1 & Training Requirements and & \\
\hline
\end{tabular}




\begin{tabular}{|c|c|c|}
\hline & MOEs & $\begin{array}{l}\text { ID Requirement } \\
\text { Supported }\end{array}$ \\
\hline 4.2 & Safety & \\
\hline 4.3 & Human factors & \\
\hline 4.4 & Maintainability & \\
\hline 4.5 & Manpower supportability & \\
\hline 5 & Cyber Security & \\
\hline 5.1 & CSET Evaluation & 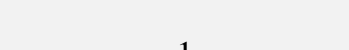 \\
\hline 5.2 & Static Code Review & \\
\hline 5.3 & Red Team Analysis & \\
\hline 6 & Economic Impact & N/A for Fort Carson \\
\hline
\end{tabular}

\subsection{Measures of Performance (MOPs)}

In order to evaluate each of the MOEs, it is necessary to collect data. The MOPs are the individual points of data collection that allow for the higher level MOEs to be qualitatively evaluated. For example, in order to calculate MOE 2.2 - System Efficiency, it is necessary to make multiple measurements such as the output of generators and the energy consumption of end-use loads. Since there is no direct electrical measurement for system wide efficiency, it is necessary to calculate the losses of the system as the difference between the generation and metered load. This requires a measurement for each generator output, all diesels and renewables, and to measure the electrical consumption of all loads. Once losses are known, it is then possible to calculate the system efficiency. As a result, MOPs can be individual measurements, values calculated from multiple measurements, or expert observations and evaluation of a particular element of SPIDERS operation.

Each of the MOEs will be qualitatively evaluated by collecting information from specific MOPs and processing the data. The ODEP will define what the specific MOPs are and the details necessary for collecting the raw data. The OAEP will then detail the process by which the raw data collected in the MOPs is converted into the evaluation of the MOEs. Appendix A provides a more complete discussion of the individual MOPs, including how each one is numerically measured, and/or evaluated. Table 3.2 through Table 3.6 show the individual MOPs for MOE 1 through MOE 5, respectively. MOE 6 - Economic Impact will not be evaluated for Phase 2, so there are no MOPs associated with it. 
While some of the cyber MOPs can be tied directly to a standard, other measurements involve using industry best practices as the benchmark. The 3-point scoring methodology for cyber MOPs follows this format, where expectations are measurements based upon industry best practices:

$1=$ failed to meet standard or expectations

$2=$ meets standard or expectations

$3=$ exceeds standard or expectations

Table 3.2: MOPs for MOE 1

\begin{tabular}{|c|c|c|}
\hline \multicolumn{3}{|c|}{ MOE 1: Effectiveness } \\
\hline MOP & MOP Name & Unit of Measure \\
\hline \multicolumn{3}{|c|}{ MOE 1.1: Sustained Operations } \\
\hline MOP 1.1.1 & Increased time & Hours \\
\hline MOP 1.1.2 & Increased time & $\%$ change \\
\hline MOP 1.1.3 & Increased mission essential asset time & Hours \\
\hline MOP 1.1.4 & Increased mission essential asset time & $\%$ change \\
\hline \multicolumn{3}{|c|}{ MOE 1.2: Additional Load Served } \\
\hline MOP 1.2.1 & Additional peak load served & $\mathrm{kW}$ \\
\hline MOP 1.2.2 & Additional energy supplied & $\mathrm{kWh}$ \\
\hline \multicolumn{3}{|c|}{ MOE 1.3: Reliability } \\
\hline MOP 1.3.1 & Additional generation resource availability & Minutes \\
\hline MOP 1.3.2 & Effective Asset Testing & Qualitative \\
\hline \multicolumn{3}{|c|}{ MOE 1.4: Power Quality } \\
\hline MOP 1.4.1 & $\begin{array}{l}\text { Electric Vehicle Supply Equipment voltage total harmonic } \\
\text { distortion (THD) }\end{array}$ & $\%$ \\
\hline MOP 1.4.2 & System frequency & $\mathrm{Hz}$ \\
\hline MOP 1.4.3 & System power factor & Unitless \\
\hline MOP 1.4.4 & Diesel Generator 1 steady state voltage & $\mathrm{V}$ \\
\hline MOP 1.4 .5 & Diesel Generator 2 steady state voltage & $\mathrm{V}$ \\
\hline MOP 1.4.6 & Diesel Generator 3 steady state voltage & $\mathrm{V}$ \\
\hline MOP 1.4 .7 & EVSE steady state voltage & $\mathrm{V}$ \\
\hline MOP 1.4.8 & Diesel Generator 1 voltage imbalance & $\%$ \\
\hline MOP 1.4.9 & Diesel Generator 2 voltage imbalance & $\%$ \\
\hline MOP 1.4 .10 & Diesel Generator 3 voltage imbalance & $\%$ \\
\hline MOP 1.4.11 & EVSE voltage imbalance & $\%$ \\
\hline
\end{tabular}


Table 3.3 MOPs for MOE 2

\begin{tabular}{|c|c|c|}
\hline \multicolumn{3}{|c|}{ MOE 2: Efficiency } \\
\hline MOP & MOP Name & Unit of Measure \\
\hline \multicolumn{3}{|c|}{ MOE 2.1: System Efficiency } \\
\hline MOP 2.1.1 & DG increased efficiency & Percent \\
\hline MOP 2.1.2 & DG reduced run time & Hours \\
\hline MOP 2.1.3 & DG reduced $\mathrm{CO} 2$ & Lbm (Pound mass) \\
\hline MOP 2.1.4 & DG reduced NOx & Lbm. \\
\hline MOP 2.1.5 & DG reduced SOx & Lbm. \\
\hline MOP 2.1.6 & DG reduced PM-10 & Lbm. \\
\hline MOP 2.1.7 & System real losses & $\mathrm{kWh}$ \\
\hline MOP 2.1.8 & System reactive losses & kVARh \\
\hline MOP 2.1.9 & System real losses & $\%$ \\
\hline MOP 2.1.10 & System reactive losses & $\%$ \\
\hline \multicolumn{3}{|c|}{ MOE 2.2: End-Use Efficiency } \\
\hline MOP 2.3.1 & End-Use real losses & $\mathrm{kWh}$ \\
\hline MOP 2.3.2 & End-Use reactive losses & $\mathrm{kVARh}$ \\
\hline MOP 2.3.3 & End-Use real losses & $\%$ \\
\hline MOP 2.3.4 & End-Use reactive losses & $\%$ \\
\hline
\end{tabular}


Table 3.4: MOPs for MOE 3

\begin{tabular}{|c|l|l|}
\hline \multicolumn{3}{|c|}{ MOE 3: Integration of Renewables } \\
\hline \multicolumn{2}{|c|}{ MOP Name } & \multicolumn{1}{|c|}{ Unit of Measure } \\
\hline \multicolumn{2}{|c|}{ MOE 3.1: PV Penetration Level } \\
\hline MOP 3.1.1 & Percent of name plate & $\%$ \\
\hline MOP 3.1.2 & Percent of peak load & $\%$ \\
\hline MOP 3.1.3 & Percent of energy supplied & $\%$ \\
\hline MOP 3.1.4 & Capacity factor & $\%$ \\
\hline
\end{tabular}


Table 3.5: MOPs for MOE 4

\begin{tabular}{|c|c|c|}
\hline \multicolumn{3}{|c|}{ MOE 4: Suitability } \\
\hline MOP & MOP Name & Unit of Measure \\
\hline \multicolumn{3}{|c|}{ MOE 4.1: Training Requirements and Material } \\
\hline MOP 4.1.1 & $\begin{array}{l}\text { User training needs } \\
\text { identified }\end{array}$ & Pre-demonstration interviews with $\mathrm{B} \& \mathrm{M}$ and stakeholders \\
\hline \multirow{3}{*}{ MOP 4.12} & \multirow{3}{*}{$\begin{array}{l}\text { Training material } \\
\text { developed }\end{array}$} & User comments \\
\hline & & Comprehensiveness \\
\hline & & Gaps \\
\hline \multicolumn{3}{|c|}{ MOE 4.2: Safety } \\
\hline MOP 4.2.1 & $\begin{array}{l}\text { Safety procedures } \\
\text { established to } \\
\text { communicate that circuits } \\
\text { are energized in absence } \\
\text { of utility power }\end{array}$ & Pre-demo interviews with DPW, B\&M, and facility managers \\
\hline MOP 4.2.2 & $\begin{array}{l}\text { Procedures incorporated } \\
\text { into SPIDERS modes }\end{array}$ & Demonstration of procedures during OD \\
\hline \multicolumn{3}{|c|}{ MOE 4.3: Human Factors } \\
\hline \multirow{2}{*}{ MOP 4.3.1 } & \multirow{2}{*}{$\begin{array}{l}\text { Non-interference } \\
\text { (unobtrusive) operation of } \\
\text { SPIDERS at supported } \\
\text { Facilities }\end{array}$} & $\begin{array}{l}\text { Same equipment and number of resets during outages with } \\
\text { and without SPIDERS; equipment logs (where available), } \\
\text { debrief, and checklists }\end{array}$ \\
\hline & & Facility process variables unchanged \\
\hline \multirow{3}{*}{ MOP 4.3.2 } & \multirow{3}{*}{$\begin{array}{l}\text { Situational awareness at } \\
\text { DPW }\end{array}$} & $\begin{array}{l}\text { HMI alarms occur simultaneously with outages; logs, } \\
\text { observation, and interviews }\end{array}$ \\
\hline & & $\begin{array}{l}\text { SPIDERS HMI displays state of system (mode of operation, } \\
\text { lines energized, facilities energized, breakers open/closed, } \\
\text { renewable production, drill-down to key components); } \\
\text { inspection of HMI }\end{array}$ \\
\hline & & $\begin{array}{l}\text { Decision hierarchy specified and demonstrated for SPIDERS } \\
\text { activation/deactivation }\end{array}$ \\
\hline MOP 4.3.3 & $\begin{array}{l}\text { HMI permits mode } \\
\text { changes and illustrates in } \\
\text { salient manner }\end{array}$ & $\begin{array}{l}\text { GUI allows operator with correct permissions to change } \\
\text { SPIDERS state: auto on/off, manual on/off, disaster mode; } \\
\text { inspection of HMI; facilities state: energize/de-energize } \\
\text { facility }\end{array}$ \\
\hline
\end{tabular}




\begin{tabular}{|c|c|c|}
\hline MOP 4.3.4 & $\begin{array}{l}\text { SPIDERS provides means } \\
\text { for error state recovery }\end{array}$ & Operators informed of error state and actions to be taken \\
\hline \multicolumn{3}{|c|}{ MOE 4.4: Maintainability } \\
\hline \multirow{2}{*}{ MOP 4.4.1 } & \multirow{2}{*}{ Access } & $\begin{array}{l}\text { Physical and software components of SPIDERS can be } \\
\text { accessed by responsible personnel }\end{array}$ \\
\hline & & Responsible personnel are identified and trained \\
\hline MOP 4.4.2 & System update procedures & $\begin{array}{l}\text { OS and IPERC update procedures developed and briefed to } \\
\text { responsible personnel }\end{array}$ \\
\hline \multirow[t]{2}{*}{ MOP 4.4.3 } & \multirow[t]{2}{*}{ Component availability } & IPC-manufactured component spares provided \\
\hline & & Plan for obtaining COTS defined \\
\hline \multicolumn{3}{|c|}{ MOE 4.5 Manpower Supportability } \\
\hline MOP 4.5.1 & $\begin{array}{l}\text { Plan for post-OD } \\
\text { incorporation of } \\
\text { SPIDERS into base } \\
\text { operations defined }\end{array}$ & Interview with B\&M and DPW managers \\
\hline MOP 4.5.2 & $\begin{array}{l}\text { DPW operators } \\
\text { responsible for SPIDERS } \\
\text { operation and } \\
\text { maintenance identified } \\
\text { and trained }\end{array}$ & Inspection of procedures \\
\hline MOP 4.5.3 & $\begin{array}{l}\text { Operations and } \\
\text { maintenance contractors } \\
\text { (e.g., Fort Carson Support } \\
\text { Services) field personnel } \\
\text { responsible for SPIDERS } \\
\text { operation and } \\
\text { maintenance identified } \\
\text { and trained }\end{array}$ & Inspection of procedures \\
\hline
\end{tabular}


Table 3.6: MOPs for MOE 5

\begin{tabular}{|c|c|c|}
\hline \multicolumn{3}{|c|}{ MOE 5: Cyber Security } \\
\hline MOP & MOP Name & Unit of Measure \\
\hline \multicolumn{3}{|c|}{ MOE 5.1: CSET Evaluation } \\
\hline MOP 5.1.1 & $\begin{array}{l}\text { Performed CSET compliance } \\
\text { review against DoD } 8500.2\end{array}$ & $\begin{array}{l}\text { Verify that the Fort Carson microgrid demonstration } \\
\text { environment is compliant with DoD } 8500.2 \\
\text { - Fort Carson microgrid is less than } 30 \% \text { compliant } \\
\text { with DoD } 8500.2 \text { (1) } \\
\text { - Fort Carson microgrid is } 30 \% \text { to } 70 \% \text { compliant with } \\
\text { DoD } 8500.2 \text { (2) } \\
\text { - Fort Carson microgrid is more than } 70 \% \text { compliant } \\
\text { with DoD } 8500.2(3)\end{array}$ \\
\hline MOP 5.1.2 & $\begin{array}{l}\text { Performed CSET compliance } \\
\text { review against NIST SP } 800- \\
82\end{array}$ & $\begin{array}{l}\text { Verify that the Fort Carson microgrid demonstration } \\
\text { environment is compliant with NIST SP } 800-82 \\
\text { - Fort Carson microgrid is less than } 30 \% \text { compliant } \\
\text { with NIST SP 800-82 (1) } \\
\text { - Fort Carson microgrid is } 30 \% \text { to } 70 \% \text { compliant with } \\
\text { NIST SP 800-82 (2) } \\
\text { - Fort Carson microgrid is more than 70\% compliant } \\
\text { with NIST SP 800-82 (3) }\end{array}$ \\
\hline MOP 5.1.3 & $\begin{array}{l}\text { DIACAP documents } \\
\text { provided for CSET reviews }\end{array}$ & $\begin{array}{l}\text { Verify } 100 \% \text { design by evaluating DIACAP documentation } \\
\text { - DIACAP documents not provided (1) } \\
\text { - DIACAP documents provided but incomplete (2) } \\
\text { - DIACAP documents provided and complete (3) }\end{array}$ \\
\hline MOP 5.1.4 & $\begin{array}{l}\text { Onsite verification of CSET } \\
\text { reviews performed }\end{array}$ & $\begin{array}{l}\text { Verify that the implemented environment is consistent with } \\
\text { 100\% Design Document by conducting interviews with } \\
\text { operators, implementers, and inspecting microgrid operational } \\
\text { systems } \\
\text { - The operational microgrid environment contains } \\
\text { vulnerabilities, components, or communication paths } \\
\text { not identified in the } 100 \% \text { Design Document (1) } \\
\text { - The operational microgrid environment is consistent } \\
\text { with the } 100 \% \text { Design Document (2) } \\
\text { The operational microgrid environment is consistent } \\
\text { with the } 100 \% \text { Design Document and incorporates } \\
\text { stronger cyber security mechanisms than required (3) }\end{array}$ \\
\hline MOP 5.1.5 & $\begin{array}{l}\text { Compared Phase } 1 \text { and Phase } \\
2 \text { CSET findings }\end{array}$ & $\begin{array}{l}\text { Verify that cyber security matures as the SPIDERS project } \\
\text { progresses } \\
\text { - CSET results show a net decrease from Phase } 1(1) \\
\text { - CSET results show no substantial change from Phase } \\
1 \text { (2) } \\
\text { - CSET results show a net improvement from Phase } 1 \\
\text { (3) }\end{array}$ \\
\hline
\end{tabular}




\begin{tabular}{|c|c|c|}
\hline MOP 5.1.6 & $\begin{array}{l}\text { Identify responsible person or } \\
\text { organization to address cyber } \\
\text { security for DoD microgrids }\end{array}$ & $\begin{array}{l}\text { Verify that a cyber security resource is identified } \\
\text { - No responsible person or organization identified (1) } \\
\text { - A responsible organization is identified (2) } \\
\text { - A responsible person within the responsible } \\
\text { organization is identified (3) }\end{array}$ \\
\hline \multicolumn{3}{|c|}{ MOE 5.2: Static Code Evaluation } \\
\hline MOP 5.2.1 & $\begin{array}{l}\text { Conducted performance tests } \\
\text { against IPERC software }\end{array}$ & $\begin{array}{l}\text { Verify that resource utilization issues do not exist in IPERC } \\
\text { source code } \\
\text { - Multiple CPU utilization or multiple memory leak } \\
\text { findings or any other severe resource utilization } \\
\text { issues were identified (1) } \\
\text { - Only minor resource utilization issues were } \\
\text { identified (2) } \\
\text { - No resource utilization findings were identified (3) }\end{array}$ \\
\hline
\end{tabular}




\begin{tabular}{|c|c|c|}
\hline MOP 5.2.2 & $\begin{array}{l}\text { Conducted static code } \\
\text { analysis security tests against } \\
\text { IPERC software }\end{array}$ & 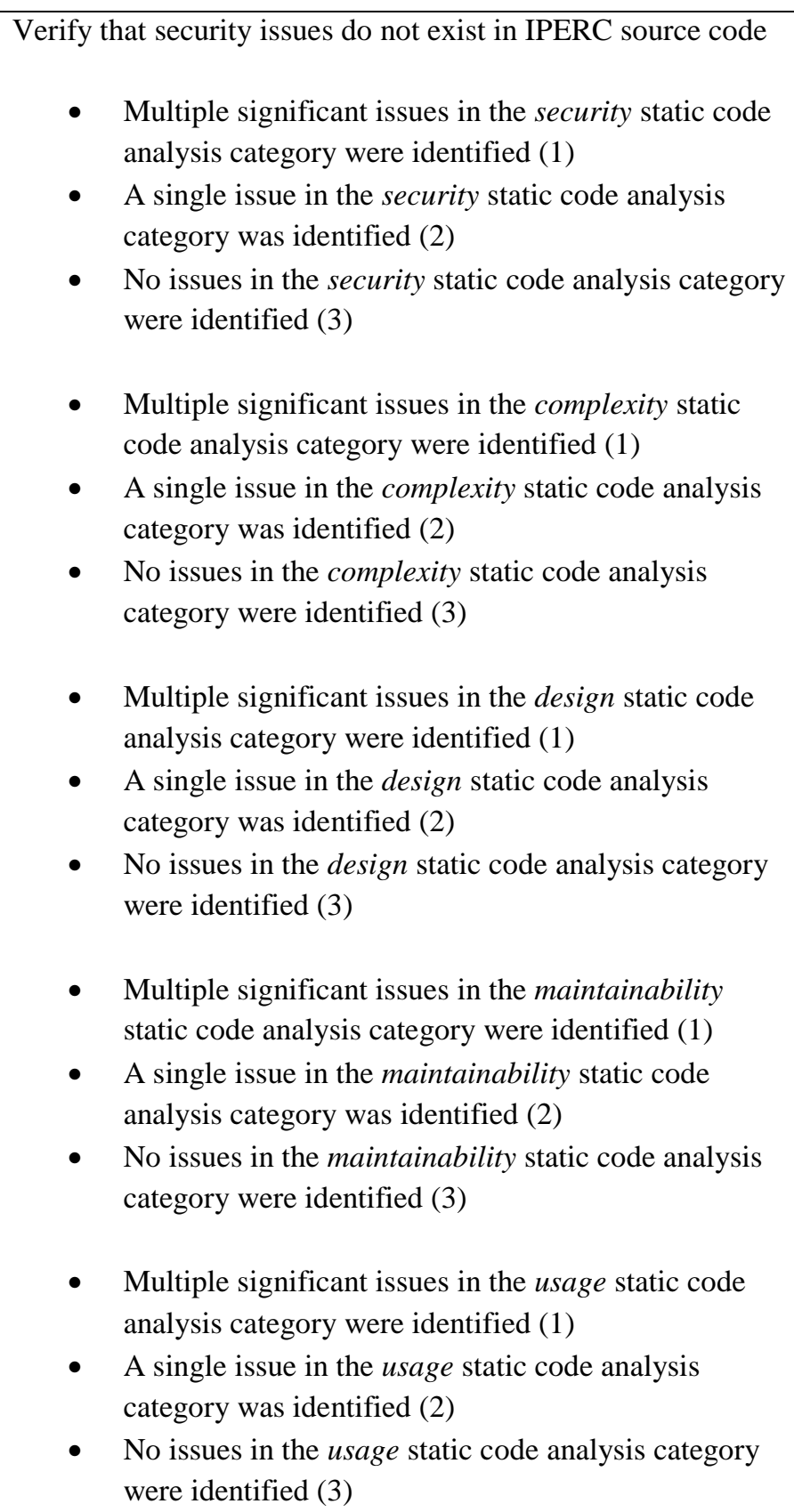 \\
\hline MOP 5.2.3 & $\begin{array}{l}\text { Evaluated IPERC mitigation } \\
\text { strategies for performance } \\
\text { findings }\end{array}$ & $\begin{array}{l}\text { Verify that effective mitigation strategies are available for all } \\
\text { performance findings } \\
\text { - Mitigation strategy recommendations not provided } \\
\text { for multiple performance findings or the mitigation } \\
\text { strategies have significant shortcomings that will } \\
\text { render them ineffective (1) } \\
\text { - Mitigation strategy recommendations not provided } \\
\text { for a single performance finding, or at most, only one } \\
\text { ineffective mitigation strategy is proposed (2) } \\
\text { - } \text { Effective mitigation strategy recommendations } \\
\text { provided for all performance findings (3) }\end{array}$ \\
\hline
\end{tabular}




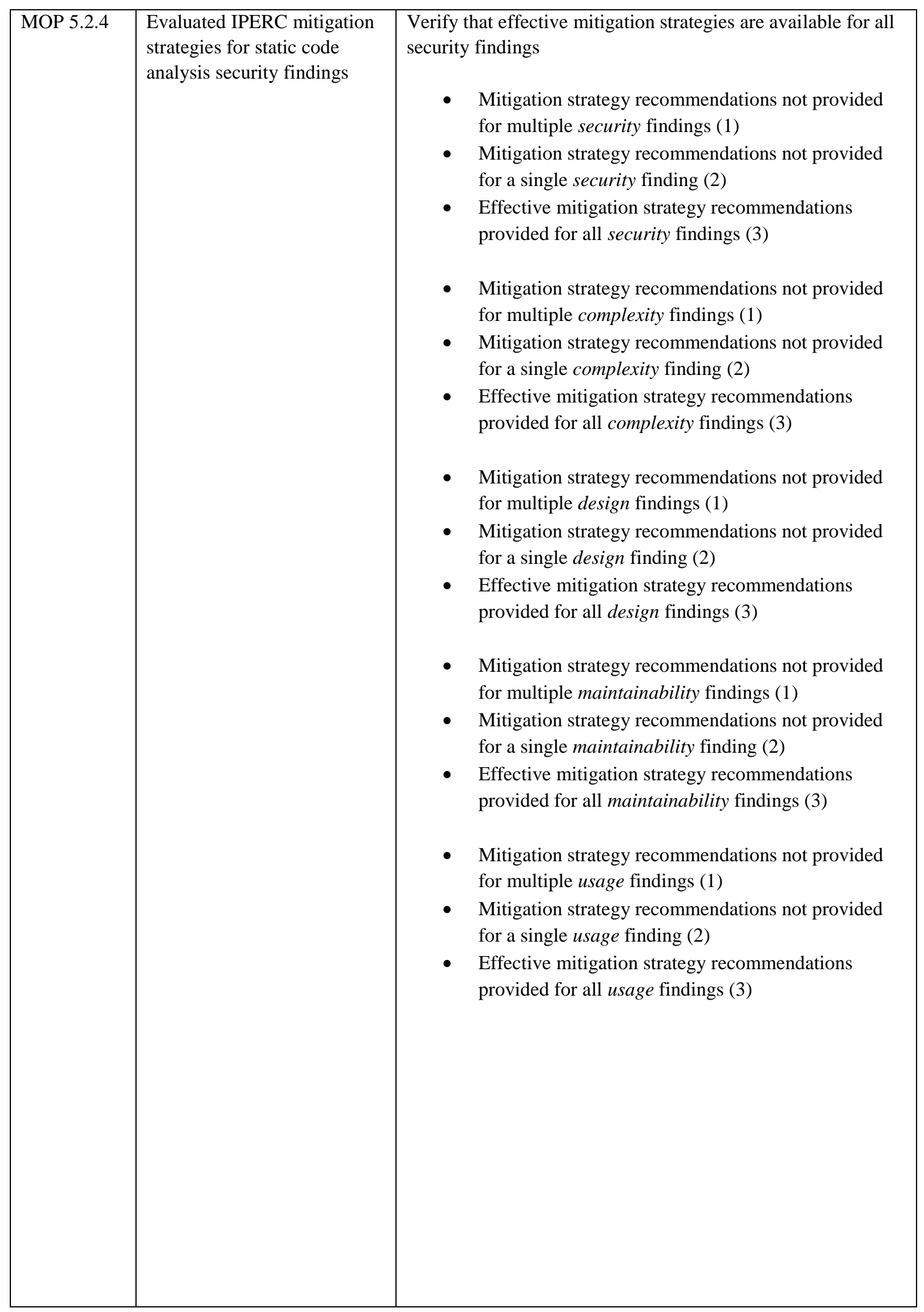




\begin{tabular}{|c|c|c|}
\hline \multicolumn{3}{|c|}{ MOE 5.3: Red Team Assessment } \\
\hline $\begin{array}{l}\text { MOP } \\
5.3 .1\end{array}$ & $\begin{array}{l}\text { PNNL staff assessed Red Team } \\
\text { capabilities prior to observation } \\
\text { of Red Team activities }\end{array}$ & $\begin{array}{l}\text { Verify that the Red Team has both the necessary level of } \\
\text { experience and tool kits to evaluate the routable and serial } \\
\text { ICS environments that comprise the operational } \\
\text { demonstration environment } \\
\text { - } \\
\text { Red Team lacks sufficient ICS experience or tools to } \\
\text { successfully evaluate the operational demonstration } \\
\text { environment (1) } \\
\text { - Red Team has some ICS experience and a set of } \\
\text { tools that may enable but not ensure successful } \\
\text { evaluation of the operational demonstration (2) } \\
\text { Red Team has sufficient ICS experience and tools to } \\
\text { ensure a successful evaluation of the operational } \\
\text { demonstration (3) }\end{array}$ \\
\hline $\begin{array}{l}\text { MOP } \\
5.3 .2\end{array}$ & $\begin{array}{l}\text { PNNL staff performed passive } \\
\text { analysis on data captured during } \\
\text { Red Team activities }\end{array}$ & 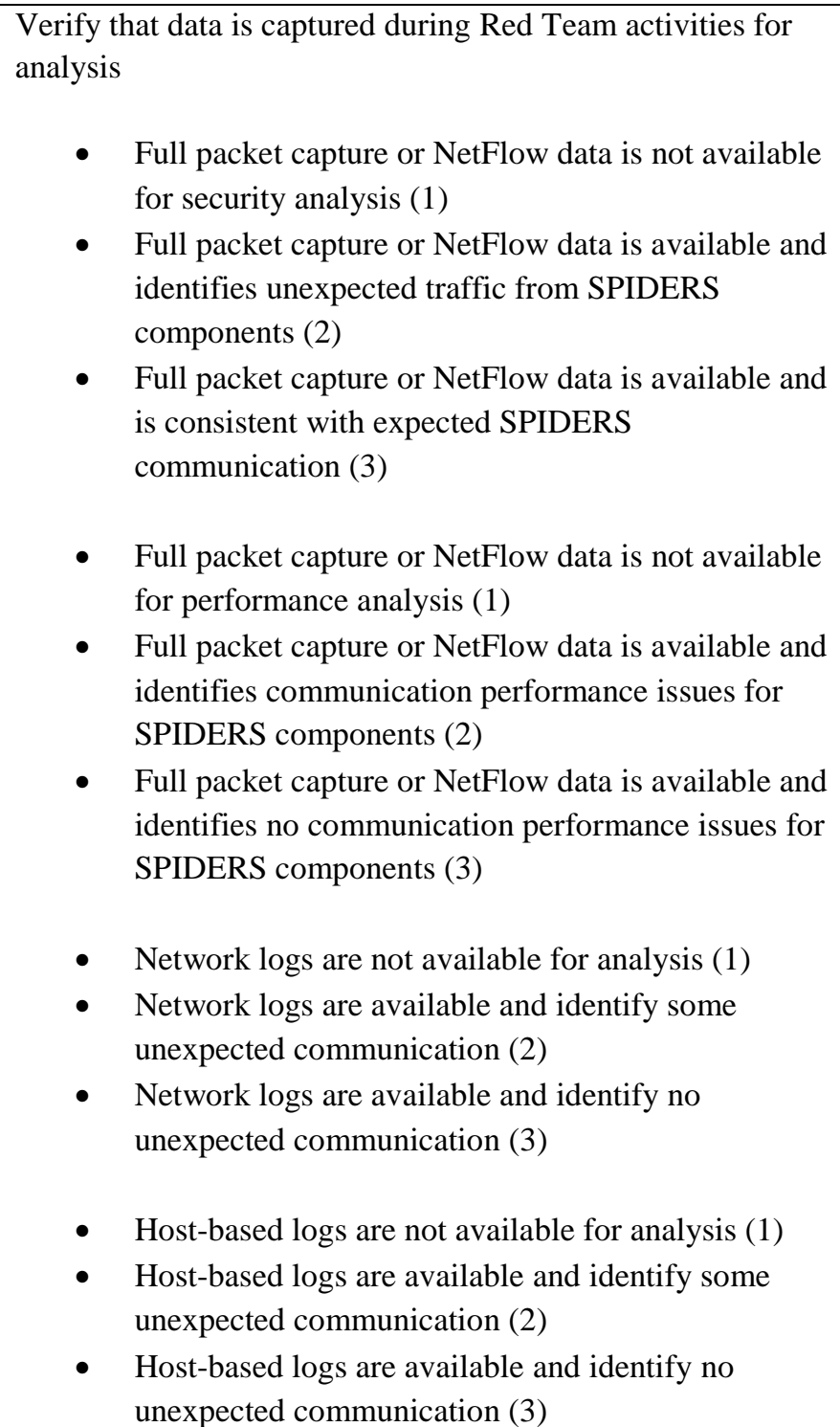 \\
\hline
\end{tabular}




\begin{tabular}{|c|c|c|}
\hline $\begin{array}{l}\text { MOP } \\
5.3 .3\end{array}$ & $\begin{array}{l}\text { The Red Team provided } \\
\text { feedback regarding additional } \\
\text { tests to be performed in a } \\
\text { laboratory setting }\end{array}$ & $\begin{array}{l}\text { Verify that the Red Team identifies additional tests for a } \\
\text { second round of laboratory testing } \\
\text { - More than ten (10) additional tests were identified } \\
\text { (1) } \\
\text { - Fewer than ten (10) additional tests were identified } \\
\text { (2) } \\
\text { - No additional tests were identified (3) }\end{array}$ \\
\hline
\end{tabular}




\subsection{Available Measurements}

Section 3 outlined all of the MOEs and MOPs for the SPIDERS Phase 2 OD. To calculate the values for the individual MOPs it is necessary to collect data. As part of the Burns \& McDonnell $100 \%$ design, the following list of measurement points has been established; shown in Table 4.1, Table 4.2, and Table 4.3. This list of points represents the data that will be automatically collected during the OD and archived in the data collection system constructed by the integrator and their subcontractors. The available measurements can be divided into three classifications: electrical, suitability, and cyber.

Electrical measurements are identified by their physical location and their sample rate. Suitability measurements can be identified by their objective and methodology. Cyber measurements can be identified by the document or information source that will be used as an input to the CSET evaluation tool. 
Table 4.1: Electrical Measurements

\begin{tabular}{|c|c|c|}
\hline Pt. \# & Measurement & Sample Rates (estimated) \\
\hline \multicolumn{3}{|c|}{ Diesel \#1 (1250 kW) } \\
\hline 1 & Real power output $(\mathrm{kW})$ & 1 per minute \\
\hline 2 & Reactive power output (kVAR) & 1 per minute \\
\hline 3 & Voltage (Vrms) & 1 per minute \\
\hline 4 & Frequency $(\mathrm{Hz})$ & 1 per day \\
\hline 5 & Fuel consumption (gal/day) & Manual \\
\hline 6 & Available fuel (gal) & Manual \\
\hline \multicolumn{3}{|c|}{ Diesel \#2 (1000 kW) } \\
\hline 7 & Real power output $(\mathrm{kW})$ & 1 per minute \\
\hline 8 & Reactive power output (kVAR) & 1 per minute \\
\hline 9 & Voltage (Vrms) & 1 per minute \\
\hline 10 & Frequency $(\mathrm{Hz})$ & 1 per day \\
\hline 11 & Fuel consumption (gal/day) & Manual \\
\hline 12 & Available fuel (gal) & Manual \\
\hline \multicolumn{3}{|c|}{ Diesel \#3 (900 kW) } \\
\hline 13 & Real power output $(\mathrm{kW})$ & 1 per minute \\
\hline 14 & Reactive power output (kVAR) & 1 per minute \\
\hline 15 & Voltage (Vrms) & 1 per minute \\
\hline 16 & Frequency $(\mathrm{Hz})$ & 1 per day \\
\hline 17 & Fuel consumption (gal/day) & Manual \\
\hline 18 & Available fuel (gal) & Manual \\
\hline \multicolumn{3}{|c|}{ Solar Plant } \\
\hline 19 & Real power output (kW) & 1 per minute \\
\hline \multicolumn{3}{|c|}{ EVSE Aggregator } \\
\hline 20 & Real power output at each EVSE $(\mathrm{kW})$ & 1 per minute \\
\hline 21 & Reactive power output at each EVSE (kVAR) & 1 per minute \\
\hline 22 & Voltage at point of interconnection (Vrms) & 1 per minute \\
\hline 23 & Voltage harmonics & 1 per minute \\
\hline \multicolumn{3}{|c|}{ Distribution System } \\
\hline 24 & System frequency $(\mathrm{Hz})$ & $60 \mathrm{~Hz}$ \\
\hline 25 & All switch status (binary) & 1 per minute \\
\hline 26 & All relay status (binary) & 1 per minute \\
\hline 27 & Real energy consumed (kWh) & 1 per 15 minutes \\
\hline 28 & Reactive energy consumed (kVARh) & 1 per 15 minutes \\
\hline
\end{tabular}


Table 4.2: Suitability Measurements

\begin{tabular}{|c|c|c|}
\hline Pt. \# & Measurement & Method \\
\hline \multicolumn{3}{|r|}{ Training } \\
\hline 29 & Training needs identified & Review user roles and requirements \\
\hline 30 & Training material & User ratings, expert review \\
\hline \multicolumn{3}{|r|}{ Safety } \\
\hline 31 & Safety procedures established & DPW and operations and maintenance contractor interviews \\
\hline 32 & $\begin{array}{l}\text { Procedures incorporated into } \\
\text { SPIDERS modes }\end{array}$ & DPW and operations and maintenance contractor demonstration \\
\hline \multicolumn{3}{|r|}{ Human Factors } \\
\hline 33 & $\begin{array}{l}\text { Non-interference (unobtrusive) } \\
\text { operation of SPIDERS at ME } \\
\text { facilities }\end{array}$ & $\begin{array}{l}\text { - } \quad \text { Number of equipment resets required } \\
\text { - } \quad \text { Process variables within tolerance range }\end{array}$ \\
\hline 34 & $\begin{array}{l}\text { Situational awareness at DPW HMI } \\
\text { and Emergency Operations Center }\end{array}$ & \begin{tabular}{|l} 
Observation and interview: \\
- Alarm logs \\
- Decision hierarchy specified and demonstrated for \\
SPIDERS activation \\
- \\
Decision hierarchy specified and demonstrated for \\
SPIDERS additional load support of MS and MD \\
facilities
\end{tabular} \\
\hline 35 & $\begin{array}{l}\text { HMI permits mode changes and } \\
\text { illustrates in salient manner }\end{array}$ & $\begin{array}{l}\text { Inspection of HMI: GUI allows operator with correct permissions } \\
\text { to change SPIDERS state: auto on/off, manual on/off, facilities } \\
\text { state: energize/de-energize facility (MD and MS facilities only), } \\
\text { etc. }\end{array}$ \\
\hline 36 & $\begin{array}{l}\text { SPIDERS provides means for error } \\
\text { state recovery }\end{array}$ & $\begin{array}{l}\text { Interview: Operators should be informed of error state and actions } \\
\text { to be taken }\end{array}$ \\
\hline \multicolumn{3}{|r|}{ Maintainability } \\
\hline 37 & Access & $\begin{array}{l}\text { Observation and interview: } \\
\text { - Physical and software components of SPIDERS can be } \\
\text { accessed by responsible personnel } \\
\text { - Responsible personnel are identified and trained }\end{array}$ \\
\hline 38 & System update procedures & $\begin{array}{l}\text { Interview: OS and IPERC update procedures developed and } \\
\text { briefed to responsible personnel }\end{array}$ \\
\hline 39 & Component availability & $\begin{array}{ll}\text { - } & \text { Plan for obtaining COTS defined } \\
\text { - } & \text { Spares provided for IPC-manufactured components }\end{array}$ \\
\hline \multicolumn{3}{|c|}{ Manpower Supportability } \\
\hline 40 & $\begin{array}{l}\text { Plan for post-OD incorporation of } \\
\text { SPIDERS into base operations } \\
\text { defined }\end{array}$ & Interview with B\&M and DPW managers \\
\hline
\end{tabular}


Table 4.3: Cyber Measurements

\begin{tabular}{|c|l|l|}
\hline Pt. \# & \multicolumn{1}{|c|}{ Document } & \multicolumn{1}{|c|}{ Method } \\
\hline 41 & B\&M 100\% Design & CSET input \\
\hline 42 & $\begin{array}{l}\text { Complete Probabilistic Risk Assessment (PRA) } \\
\text { Package }\end{array}$ & CSET input \\
\hline 43 & Operator Interviews & CSET input \\
\hline
\end{tabular}




\subsection{Operational Assessment Execution Plan (OAEP)}

The OAEP details the method by which the data collected from the OD is post processed to determine if SPIDERS successfully met the four critical requirements of the ID. For Phase 2, the four critical requirements are assumed to be met if the five MOEs are successfully met. Each of the five MOEs must be evaluated as acceptable; a failure of a single MOE will be regarded as a failure of the overall OD.

\subsection{Success Criteria for MOE 1: Effectiveness}

In order for MOE 1 to be considered successful, a number of criteria must be met. Determining if the criteria are met is accomplished via the use of the individual MOPs within the MOE. The criteria that must be met are:

1) For a given amount of diesel fuel, the SPIDERS enabled microgrid must be able to operate as long as or longer than a system without SPIDERS.

2) When the SPIDERS-enabled microgrid is in operation, it must be at least as reliable as a system without SPIDERS.

3) All standard fundamental electrical characteristics must be within industry standards; e.g., voltage, frequency, imbalance, and harmonic content.

\subsection{Success Criteria for MOE 2: Efficiency}

In order for MOE 2 to be considered successful, a number of criteria must be met. Determining if the criteria are met is accomplished via the use of the individual MOPs within the MOE. The criteria that must be met are:

1) The system as a whole should be electrically more efficient. This includes the sum of generation, distribution, and loads.

2) Overall diesel generator emissions must be lower than a system that is not SPIDERSenabled.

\subsection{Success Criteria for MOE 3: Renewables Integration}

In order for MOE 3 to be considered successful, a number of criteria must be met. Determining if the criteria are met is accomplished via the use of the individual MOPs within the MOE. The criteria that must be met are:

1) During normal operations, the SPIDERS-enabled microgrid must be able to make use of renewable generation sources. For Phase 2, this specifically applies to solar photovoltaic (PV). 
2) The integration of renewables must be sustained over the entire test period. For example, a lack of solar energy provided to the microgrid, as long as the units are still connected, is considered acceptable.

\subsection{Success Criteria for MOE 4: Suitability}

In order for MOE 4 to be considered successful, a number of criteria must be met. Determining if the criteria are met is accomplished via the use of the individual MOPs within the MOE. The criteria that must be met are:

1) The operations of a SPIDERS-enabled microgrid must be unobtrusive to the operators.

2) The system must ensure operator situational awareness.

3) The system must have the same level of personnel safety as the current system.

\subsection{Success Criteria for MOE 5: Cyber Security}

In order for MOE 5 to be considered successful, a number of criteria must be met. Determining if the criteria have been met is accomplished via the use of the individual MOPs within the MOE. The answers to the requirements associated with DoD 8500.2 and NIST SP800-82, and captured by the CSET tool, determine compliance with these standards. Industry best practices will be used to measure compliance for the static code analysis activity.

1) Compliance with DoD 8500.2, as determined by a CSET evaluation.

2) Compliance with NIST SP 800-82, as determined by a CSET evaluation.

3) Compliance with secure coding practices as determined by static code analysis tools.

4) Compliance with best practices as determined by a Red Teaming activity against the operational environment. As of the IAP publication date, the Red Teaming activity is scheduled for the April to June 2014 timeframe. The time lag requires that Red Team assessment results be captured in a separate document.

A complete CSET evaluation will give a percent compliance with the two standards and identify how compliance can be improved. CSET does not provide a set of acceptable values; instead it makes the assumption that cyber assets can never be $100 \%$ secure. The results will be in terms of how compliant the system is and what could be done to further improve it.

\subsection{Mapping Measurement Points to MOPs}

Each of the five MOEs is supported by a number of MOPs. Table 5.1 shows the specific measurement points that are used to calculate the individual MOPs. The equations and algorithms used to evaluate the MOPs based on measurements can be found in Appendix A. The MOPs will then be used to support the evaluations of the MOEs. 
Table 5.1: Mapping of Measurement Values to MOPs

\begin{tabular}{|c|c|c|c|}
\hline \multicolumn{4}{|c|}{ MOP to Measurement Point Mapping } \\
\hline MOP & MOP Name & Unit of Measure & Measurement Points \\
\hline MOP 1.1 .1 & Increased time & Hours & $5,10,15$ \\
\hline MOP 1.1.2 & Increased time & Percent change & $5,10,15$ \\
\hline MOP 1.1 .3 & Increased mission essential asset time & Hours & $5,10,15$ \\
\hline MOP 1.1.4 & Increased mission essential asset time & $\%$ change & $5,10,15$ \\
\hline MOP 1.2 .1 & Additional peak load served & $\mathrm{kW}$ & $1,6,11,16,17,27$ \\
\hline MOP 1.2 .2 & Additional energy supplied & $\mathrm{kWh}$ & $1,6,11,16,17,27$ \\
\hline MOP 1.3 .1 & $\begin{array}{l}\text { Additional generation resource } \\
\text { availability }\end{array}$ & Minutes & $1,2,7,8,13,14,19,20$ \\
\hline MOP 1.3 .2 & Effective Asset Testing & N/A & Qualitative \\
\hline MOP 1.4 .1 & EVSE voltage THD & $\%$ & 20 \\
\hline MOP 1.4 .2 & System frequency & $\mathrm{Hz}$ & $4,10,16$ \\
\hline MOP 1.4 .3 & System power factor & $\mathrm{pf}$ & $1,2,7,8,13,14,19,20,21$ \\
\hline MOP 1.4 .4 & Diesel Generator 1 steady state voltage & $\mathrm{V}$ & 3 \\
\hline MOP 1.4 .5 & Diesel Generator steady state voltage & $\mathrm{V}$ & 9 \\
\hline MOP 1.4 .6 & Diesel Generator 3 steady state voltage & $\mathrm{V}$ & 15 \\
\hline MOP 1.4 .7 & EVSE steady state voltage & $\mathrm{V}$ & 22 \\
\hline MOP 1.4 .8 & Diesel Generator 1 voltage imbalance & $\%$ & 3 \\
\hline MOP 1.4 .9 & Diesel Generator 2 voltage imbalance & $\%$ & 9 \\
\hline MOP 1.4 .10 & Diesel Generator 3 voltage imbalance & $\%$ & 15 \\
\hline MOP 1.4.11 & EVSE voltage imbalance & $\%$ & 22 \\
\hline MOP 2.1.1 & DG increased efficiency & Percent & $1,2,5,7,8,11,13,14,17$ \\
\hline MOP 2.1.2 & DG reduced run time & Hours & $1,7,13$ \\
\hline MOP 2.1.3 & DG reduced $\mathrm{CO} 2$ & Lbm. & $1,2,5,7,8,11,13,14,17$ \\
\hline MOP 2.1.4 & DG reduced $\mathrm{CO} 2$ Intensity & Lbm./Watt-Hour & $1,2,5,7,8,11,13,14,17$ \\
\hline MOP 2.1.5 & DG reduced NOx & Lbm. & $1,2,5,7,8,11,13,14,17$ \\
\hline MOP 2.1.6 & DG reduced NOx Intensity & Lbm./Watt-Hour & $1,2,5,7,8,11,13,14,17$ \\
\hline MOP 2.1.7 & DG reduced SOx & Lbm. & $1,2,5,7,8,11,13,14,17$ \\
\hline MOP 2.1.8 & DG reduced SOx Intesnity & Lbm./Watt-Hour & $1,2,5,7,8,11,13,14,17$ \\
\hline MOP 2.1.9 & DG reduced PM-10 & Lbm. & $1,2,5,7,8,11,13,14,17$ \\
\hline MOP 2.1.10 & DG reduced PM-10 Intensity & Lbm./Watt-Hour & $1,2,5,7,8,11,13,14,17$ \\
\hline MOP 2.1.11 & System real losses & $\mathrm{kWh}$ & $1,7,13,19,20,27$ \\
\hline MOP 2.1.12 & System reactive losses & kVARh & $2,8,14,21,28$ \\
\hline MOP 2.1.13 & System real losses & $\%$ & $1,7,13,19,20,27$ \\
\hline MOP 2.1.14 & System reactive losses & $\%$ & $2,8,14,21,28$ \\
\hline MOP 2.2.1 & End-Use real losses & $\mathrm{kWh}$ & \\
\hline MOP 2.2.2 & End-Use reactive losses & kVARh & \\
\hline MOP 2.2.3 & End-Use real losses & $\%$ & \\
\hline
\end{tabular}




\begin{tabular}{|c|l|l|l|}
\hline \multicolumn{5}{|c|}{ MOP to Measurement Point Mapping } \\
\hline MOP & \multicolumn{1}{|c|}{ MOP Name } & Unit of Measure & Measurement Points \\
\hline MOP 2.2.4 & End-Use reactive losses & $\%$ & \\
\hline MOP 3.1.1 & Percent of name plate & $\%$ & 19 \\
\hline MOP 3.1.2 & Percent of peak load & $\%$ & $19,1,2,7,8,13,14,20,21$ \\
\hline MOP 3.1.3 & Percent of energy supplied & $\%$ & $19,1,2,7,8,13,14,20,21$ \\
\hline MOP 3.1.4 & Capacity factor & $\%$ & $19,1,2,7,8,13,14,20,21$ \\
\hline
\end{tabular}




\subsection{References}

[1] Department of Defense Instruction 8500.2, February 6, 2003.

[2] National Institute of Standards and Technology, "Guide to Industrial Control System (ICS) Security", Special Publication 800-82.

[3] IEEE Guide for Electric Power Distribution Reliability Indices, IEEE Std. 1366-2003.

[4] American National Standard for Electrical Power Systems and Equipment-Voltage Ratings (60 Hertz), American National Standards Institute C84.1-2006.

[5] IEEE Recommended Practices and Requirements for Harmonic Control in Electric Power Systems, IEEE Std. 519-1992.

[6] WECC Coordinated Off-Nominal Frequency Load Shedding and Restoration plan, Western Electricity Coordinating Council, April 28, 2010.

[7] Interconnection Standards for Qualified Facilities, Colorado Springs Utilities, August 2011. 


\section{Appendix A: SPIDERS Measures of Effectiveness (MOEs)}

The MOEs and MOPs for SPIDERS have been developed by the OTA and approved by the OM and IMT. This appendix gives the process by which each of the MOPs is explicitly determined.

\section{A.1 MOE 1: Effectiveness}

MOE 1 will address the ability of SPIDERS to effectively extend the time that essential operations can be supported on a military installation during utility power outage. MOE 1 will quantify the ability to maintain essential operations past 80 hours. In particular, estimates will be made for the length of time the microgrid extends essential operations and the additional amount of non-essential load that can also be supported through the use of renewable resources. In addition, the effectiveness of the microgrid in maintaining reliable and quality power supplies will be addressed.

\section{A.1.1 MOP 1.1: Sustained Operations}

MOP 1.1 will address the effectiveness of the microgrid to extend mission operations past 80 hours. This will include both mission-essential and highly-desired (but not essential) load categories. Most of the loads for Phase 2 are defiend as essential loads. Three additional buildings are added into the microgrid as secondary loads. It should also be noted that the essential loads are only served in isolation during traditional operations. Once the microgrid enters the SPIDERS mode of operation, energy is provided to all of the buildings listed above, with no designation between "essential loads" and "lower priority loads".

Standard operating practice is to maintain a fuel supply to energize and operate essential loads for much longer than 80 hours. However, since the test will only encompass an 80-hour period, measurement data from this time period will be used to estimate the additional operation time provided by the inclusion of renewable resources and the operation of the microgrid beyond the 80-hour operating window. Estimates will be made for the length of operation possible under traditional operating conditions without renewable energy resources and for the length of operation with renewable energy resources integrated into the microgrid. The differential, in hours and normalized to a 80-hour period, will determine the effectiveness of the microgrid to extend connected-load operations. It should be noted that if test conditions are not conducive to a reasonable test of the system (e.g., three sunless days), the estimates will take into account the potential of the renewable resources and provide a range of effectiveness.

\section{A.1.1.1MOP 1.1:1. Increased Runtime}

With the second level of loads in the Phase 2 demonstration, more than just the essential loads will be energized by the SPIDERS microgrid. During traditional microgrid operations, only the essential load buildings would be served. However once the system enters SPIDERS operation, all of the load priority levels will be served, resulting in a potential for significantly more load on 
the generators. As such, the run-time past 80 hours will likely be negative for the full load case, as compared to the base, essential-only loading case. Rather than a single number quantifying the result, both an "essential-load-only" and "full-load-served" set of metrics will be provided. Unless a period of "essential-load-only" service exists for a significant portion of the operational demonstration, this operation technique will be estimated based on initial SPIDERS start up data and additional building load information.

Fuel consumption calculations during both microgrid and estimated normal operations (MOP 2.1.1) will be used to determine a percent change in run-time due to the use of resources other than diesel. At this time, fuel measurements will be acquired manually by examining float-style gauges attached to each generator. Hourly (or daily, at a minimum) manual observations must be conducted. Manual measurements will be taken, so precision of the fuel level display device will be noted and utilized to perform an "error propagation" analysis in the final UAR values.

Fuel consumption levels will be validated using generator data sheets. Fuel consumption curves will be used in conjunction with IPERC-measured power output to estimate fuel consumption by the generators. Significant deviations between the observed values and computed values will need to be addressed in the final metrics.

The percent change in run time will be calculated for each diesel generator as shown in equation (A.1), for "full-SPIDERS-operation" mode (essential and non-essential loads).

$$
\text { change in run time }(\%)=\left(\operatorname{average}\left(\frac{f_{\text {con }}\left(t_{1 \ldots 3}\right)}{f_{\text {con_trad }}\left(t_{1 \ldots 3}\right)}\right)-1\right) * 100
$$

where:

$\begin{array}{ll}t_{1 \ldots 3} & \text { indicates each day of the three day demonstration, } \\ f_{\text {con }} & \text { is the fuel consumption under microgrid operation during day } 1,2, \text { or } 3, \\ f_{\text {con_trad }} & \text { is the estimated fuel consumption under normal operation during day } 1,2, \\ \text { or } 3 . & \end{array}$

\section{A.1.1.2MOP 1.1.2: Increased Time}

MOP 1.1.2 will represent the result of MOP 1.1.1 in hours, rather than percentage. As with MOP 1.1.1, this value will represent full SPIDERS operation (essential and non-essential loads), and may result in a negative value for the demonstration. The change in run time will then be used to extrapolate how much longer than 80 hours the systems would be able to operate, as shown in equation (A.2).

$$
\text { Hours past } 80=\text { change in run time }(\%) * 80 \text { hours }
$$


For example, if fuel consumption is estimated to decrease from 500 gals to 400 gals in the 24 hour period, the percent change in run time would be $25 \%$, or 18 hours beyond the 80 hour original window. To define the best case scenario for hours past 80 , the "best day", or the day with the greatest fuel use reduction, will also be used to calculate a maximum hours past 80 . These two numbers will be reported in conjunction as the most likely hours past 80 and the greatest potential for hours past 80 to define a likely range of results.

\section{A.1.1.3MOP 1.1.3: Increased Mission Essential Asset Runtime}

MOP 1.1.3 addresses the effectiveness of the microgrid to extend mission operations past 80 hours for only the mission essential assets. This analysis will only include the mission essential buildings. Other buildings are assumed to be disconnected if this mode was ever active, maximizing resource availability to the essential buildings.

MOP 1.1.3 will be calculated nearly identical to MOP 1.1.1. However, only mission-essential buildings will be considered in the energy and fuel consumption calculations. This will require taking the building load and estimating fuel consumption from generator information sheets and values calculated from the "essential and non-essential loaded" SPIDERS demonstration.

\section{A.1.1.4MOP 1.1.4: Increased Mission Essential Asset Time}

MOP 1.1.4 will represent the result of MOP 1.1.3 in hours, rather than percentage. It will be calculated identical to MOP 1.1.2, but using MOP 1.1.3 in place of MOP 1.1.1.

\section{A.1.2 MOE 1.2: Additional Load}

MOE 1.2 will address the effectiveness of the microgrid in providing power to additional, noncritical loads that would not normally be served during critical or backup operation. Non-critical, but desirable loads in long term emergency situations may include emergency staging areas, mess halls, or other load which are pre-designated during the design process. These loads may be powered on or off during critical operations at various times. The goal of MOE 1.2 is to capture the amount and type of additional, non-critical load that was supported during critical operations due to the use of a microgrid with renewable resources. The additional load of secondary buildings are categorized as supported non-critical load during Phase 2.

\section{A.1.2.1 MOP 1.2.1: Additional Peak Load Served}

This metric is designed to capture the effectiveness of the microgrid in providing additional generation resources during peak load periods. This will be measured as the change between the peak real power measured during traditional islanded operations (serving only the critical operations loads) and the peak real power measured during SPIDERS operations, with the additional loads enabled. Additional peak load served will effectively be the additional "nonessential" buildings powered as part of the SPIDERS demonstration. The metric will be calculated as: 
1) Measure active power, $P_{\text {total }}(t)$, for the total system load for each time period specified, $d t$.

2) Determine the peak power consumption time when the additional loads are present, $P_{\text {total }}\left(t_{\text {peak }}\right)$.

3) Determine the power consumption of the critical loads during that time, $P_{\text {critical }}\left(t_{\text {peak }}\right)$.

4) Calculate the additional load served using equation (A.3):

$$
\text { Additional Load }=P_{\text {total }}\left(t_{\text {peak }}\right)-P_{\text {critical }}\left(t_{\text {peak }}\right)
$$

Note that this metric computes the additional load served at the peak demand time of the additional load. The peak time serving only the critical loads may not be coincidental and occur at a different time interval.

\section{A.1.2.2 MOP 1.2.2: Additional Energy Supplied}

This metric is designed to capture the additional amount of energy supplied to the end-use loads due to the operation of the microgrid. This metric will be calculated by:

1) Measure active power, $P_{\text {total }}(t)$, for the total system load for each time period specified, $d t$.

2) Determine the active power portion of Ptotal(t) that is associated with the critical loads for each time period specified, $\mathrm{dt}$.

3) Calculate the total energy consumed by the loads using equation (A.4):

$$
E_{\text {total }}=\int_{t=0}^{\text {end of } \mathrm{OD}} P_{\text {total }}(t) d t
$$

4) Calculate the energy consumed by the critical loads using equation (A.5):

$$
E_{\text {critical }}=\int_{t=0}^{\text {end of } \mathrm{OD}} P_{\text {critical }}(t) d t
$$

5) Calculate the additional energy supplied to the non-critical loads, $E_{\text {Additional }}$, using equation (A.6):

$$
E_{\text {Additional }}=E_{\text {total }}-E_{\text {critical }}
$$




\section{A.1.3 MOE 1.3: Reliability}

MOE 1.3 addresses the effectiveness of the microgrid in providing power service to the system. For many power systems applications and distribution-level analyses, utilizing the IEEE 13662003 metrics is a method to quantify the overall reliability of the power on a system [3]. However, for the shorter time frame of the OD ( 80 hours) and the microgrid nature of the system, these metrics are not the best measures of reliability. For the purposes of the SPIDERS evaluation, reliability is broken into two primary metrics: additional resource availability and additional loads served.

\section{A.1.3.1 MOP 1.3.1: Additional Generation Resource Availability}

One measure of reliability in the microgrid is how resilient the grid is to a loss of generation. During the traditional microgrid operation of Fort Carson, a loss of a generator would remove the associated critical load from operation. Under the SPIDERS mode of operation, the generators are often loaded more efficiently, which can include the shutdown of an unneeded generator. Unlike the traditional operation, there is now an additional resource available to come online and serve additional critical load. While not directly maintaining " $N-1$ " stability (the grid can survive as is with the loss of a single element), it does provide an additional resiliency to failure for the microgrid.

Given the proposed operation plan for the Phase 2 demonstration, it is unexpected that any generator will enter a shutdown state. If capacity above the critical loads is available, the secondary loads and electric vehicles will absorb excess generation. Because of this, direct measurement of "generator idle time" will not capture the capability. However, the categorized nature of the loads for the OD indicates that if one generator failed on the system, appropriate secondary loads would be shed to maintain system critical operations. As such, potential generator idle time will be estimated from the generator sizes and total power consumption of the critical operations loads.

To estimate the generator downtime, the amount of generation above the critical load requirement must be larger than a generator in the fleet (presumably the $900 \mathrm{~kW}$ diesel generator). To compute this value and determine the downtime:

1) Compute the total complex generation available from all diesel generators, the PV array, and the electric vehicle fleet, $S_{g e n}(t)$, for the duration of the OD using equation (A.7):

$$
S_{g e n}(t)=S_{1250 k W}(t)+S_{1000 k W}(t)+S_{900 k W}(t)+S_{P V}(t)+S_{E V}(t)
$$

where $S_{1250 \mathrm{~kW}}, S_{1000 \mathrm{~kW}}$, and $S_{900 \mathrm{~kW}}$ represent the power output of the $1250 \mathrm{~kW}, 1000 \mathrm{~kW}$, and $900 \mathrm{~kW}$ diesel generators, respectively. $S_{P V}$ represents the power output from the photovoltaic array. $S_{E V}(t)$ represents power "generated" into the grid by the electric vehicles. Note that this will be counted as negative during periods of electric vehicle 
battery charging. The EVs will also not count towards the threshold of the " $N-1$ " level, with the $900 \mathrm{~kW}$ diesel generator still serving that threshold.

2) Determine the critical load power consumption, $S_{\text {critical }}(t)$ by summing all mission essential building load.

3) Determine the intervals in which there is excess "critical load generator capacity" on the system using equation (A.8):

$$
\operatorname{ExcessGen}(t)= \begin{cases}1 & \text { for }\left|S_{g e n}(t)-S_{\text {critical }}(t)\right| \geq 900 \mathrm{kVA} \\ 0 & \text { for }\left|S_{\text {gen }}(t)-S_{\text {critical }}(t)\right|<900 \mathrm{kVA}\end{cases}
$$

for all $t$ in the OD interval.

4) Given the constraints of generator cycling, ignore any intervals of $\operatorname{ExcessGen}(t)$ that are less than 15 minutes. To compute the total additional resource availability time, use equation (A.9):

$$
\text { Time }_{\text {AdditionaAvailability }}=\sum \text { ExcessGen }(t) \mid t_{o f f}>15 \text { minutes }
$$

where $t_{\text {off }}$ represents the continuous blocks where the required generation has $900 \mathrm{kVA}$ or greater excess capacity (ExcessGen $(t)$ is 1$)$.

Positive values are an indication of how many minutes the microgrid operated with effectively " $N-1$ " mitigation capabilities.

\section{A.1.3.2 MOP 1.3.2: Effective Assset Testing}

As part of the SPIDERS installation and operation process, many of the generators and power distribution assets are used beyond their original deployments. This can often result in more frequent use of the devices, as well as higher capacity usage or moving further up a device's rating. While qualitative, this metric will attempt to capture any additional benefits the SPIDERS deployment offers as a result of testing the assets more rigorously than annual testing.

For example, a $600 \mathrm{~kW}$ generator may serve a $300 \mathrm{~kW}$ building in traditional operations. Under SPIDERS, this generator may run all the way up to its $600 \mathrm{~kW}$ rating (allowing more load to come online, or allowing another generator to turn off). In the process of serving this greater load, the operational limits of the $600 \mathrm{~kW}$ generator are examined, as well as any interconnecting devices. If the $600 \mathrm{~kW}$ generator caps out at $585 \mathrm{~kW}$, due to either physical limitations or other device limitations, that capacity is known for future usage. In a period of critical microgrid need, knowing these upper limits accurately can lead to better asset utilization and fewer problems. 


\section{A.1.4 MOE 1.4: Power Quality}

Power quality metrics will be applied to ensure that the microgrid is supplying ac power to the end-use loads that will not affect the lifetime of the equipment or the operation of sensitive loads. Metrics from IEEE-519, IEEE Recommended Practices for Harmonic Control in Electrical Power Systems, will focus on the ability of the generators and other power supplies to supply sinusoidal voltages, especially when considering non-linear loads and various power converters. Metrics from ANSI C84.1-2006, American National Standard for Electric Power Systems and Equipment - Voltage Ratings $(60 \mathrm{~Hz}$ ) [4] will focus on steady-state voltage and the ability of the microgrid to supply steady, balanced voltage at each load. The metrics to be applied for power quality, and their allowable ranges, are shown in Table A.1.

Table A.1: Power Quality Metrics

\begin{tabular}{|c|c|}
\hline Metric & Allowable Range \\
\hline Total harmonic distortion (THD) & $\begin{array}{l}>1 \text { hour: } 0-5 \% \\
<1 \text { hour: } 0-7.5 \%\end{array}$ \\
\hline Frequency & $\begin{array}{c}\text { Standard: } 59.40-60.60 \mathrm{~Hz} \\
\text { Critical: } 58.40-61.60 \mathrm{~Hz} \\
\text { Emergency: } 57.00-61.70 \mathrm{~Hz}\end{array}$ \\
\hline Power factor & 0.95 lagging -0.9 leading \\
\hline Steady state voltage & $\begin{array}{l}\text { Less than 600V: } \\
\quad>5 \text { minutes: } 0.950-1.050 \mathrm{puV} \\
\quad>1 \text { minute: } 0.917-1.058 \mathrm{puV} \\
\quad<1 \text { minute: } 0.600-1.100 \mathrm{puV} \\
\\
\text { Greater than } 600 \mathrm{~V}: \\
\quad>5 \text { minutes: } 0.975-1.05 \mathrm{puV} \\
\quad>1 \text { minute: } 0.950-1.058 \mathrm{puV} \\
\quad<1 \text { minute: } 0.600-1.100 \mathrm{puV} \\
\end{array}$ \\
\hline Voltage Imbalance & $\begin{array}{l}0-1 \% \\
0-3 \% \\
0-5 \%\end{array}$ \\
\hline
\end{tabular}

Measurements will be made prior to the Operational Demonstration during both standard gridconnected operation and diesel generation only. This will be used to provide a baseline for standard operation. While it is expected that the microgrid will operate within the standards defined in Table A.1, some exceptions may be made for metrics which greatly exceed these standards during normal or pre-SPIDERS operation.

\section{A.1.4.1 MOP 1.4.1: Voltage THD}

Total Harmonic Distortion (THD) is a measure of the total harmonic distortion, or a measure of the presence of multiple frequencies as compared to the desired sine wave at the fundamental frequency $(60 \mathrm{~Hz})$. This is greatly affected by the operation of power converters and inverters, 
and excessive THD can create undesired waste heat leading to component damage. It is defined as shown in equation (A.10):

$$
\mathrm{THD}=100 \% * \sqrt{\frac{\text { sum of all squares of amplitude of all harmonics }(\mathrm{h}=1 \ldots . .35, \mathrm{odd})}{\text { square of the amplitude of } 60 \mathrm{~Hz}}}
$$

At each generation interconnection point the THD will be measured and recorded on a 1-minute basis with an accuracy of $\mathrm{h}=1 \ldots 35$ (odd) harmonics, requiring a sampling rate of 2,400 Hz.

Over long periods of time (greater than one hour), voltage THD should not be greater than $5 \%$. This value will be averaged over a one-hour period. Over shorter periods of time (less than one hour), voltage THD should not be greater than 7.5\%; however, as this limit is typically not applied, this will not be considered a metric for voltage THD [5]. It is also practical that these limits may be exceeded over very short time periods, especially during motor or generator startup or shutdown periods. As such, short term excursions (two successive minutes or five total minutes per hour) above $7.5 \%$ will be considered acceptable, and disregarded from the average voltage THD value.

\section{A.1.4.2 MOP 1.4.2: System Frequency}

Maintaining system frequency near the fundamental frequency of $60 \mathrm{~Hz}$ is important for safe and reliable operation of equipment and system stability, mainly due to interactions between rotating machines, as most power converters and inverters can now handle wide ranges of frequency input and output. The Western Electricity Coordinating Council guidelines for system frequency require values between $59.4 \mathrm{~Hz}$ and 60.6 during normal operations [6]. Excursions from this range are handled in a union of frequency ranges, as described in Table A.2 below. For example, a frequency excursion of $57.4 \mathrm{~Hz}$ would be allowed for 7.5 seconds, so long as the frequency hadn't been below $58.4 \mathrm{~Hz}$ for more than 30 seconds or below $59.4 \mathrm{~Hz}$ for more than 3 minutes.

Table A.2: WECC Frequency Operational Guidelines [6]

\begin{tabular}{|l|l|l|}
\hline \multicolumn{3}{|c|}{ WECC Frequency Guidelines } \\
\hline $\begin{array}{l}\text { Under-frequency } \\
\text { Limit }\end{array}$ & $\begin{array}{l}\text { Over-frequency } \\
\text { Limit }\end{array}$ & $\begin{array}{l}\text { WECC Minimum } \\
\text { Time }\end{array}$ \\
\hline$>59.4 \mathrm{~Hz}$ & $<60.6 \mathrm{~Hz}$ & N/A (normal) \\
\hline$\leq 59.4 \mathrm{~Hz}$ & $\geq 60.6 \mathrm{~Hz}$ & 3 minutes \\
\hline$\leq 58.4 \mathrm{~Hz}$ & $\geq 61.6 \mathrm{~Hz}$ & 30 seconds \\
\hline$\leq 57.8 \mathrm{~Hz}$ & $\geq 61.6 \mathrm{~Hz}$ & 7.5 seconds \\
\hline$\leq 57.3 \mathrm{~Hz}$ & $\geq 61.6 \mathrm{~Hz}$ & 45 cycles \\
\hline$\leq 57 \mathrm{~Hz}$ & $>61.7 \mathrm{~Hz}$ & Instantaneous Trip \\
\hline
\end{tabular}

System frequency of the microgrid will be measured on a one-second interval over the course of the test. The microgrid should operate at all times within the critical operation band. 
Additionally, the average frequency through the entirety of the test should be within the standard range. If the microgrid exceeds the critical or emergency limits, generator controls should be engaged to provide an automatic or over-speed trip. These requirements will be relaxed during the initial startup phase of the microgrid (first five minutes after disconnect from grid operations).

\section{A.1.4.3 MOP 1.4.3: System Power Factor}

Excessive leading or lagging power factors can lead to decreased system efficiency, or in extreme cases, equipment damage. Colorado Springs Utilities requirements for power factor are between 0.90 lagging and 0.90 leading for interconnection of generation resources [7]. However, as power factor is normally dependent upon load behavior and not generation resources, this metric will not be used to evaluate the effectiveness of the microgrid operation, but rather to suggest further efficiency improvements. Real and reactive power flows will be measured at the load center and at each generation. If power factors exceed 0.90 leading or lagging, suggestions may be made for improving power factor.

\section{A.1.4.4 MOP 1.4.4 - MOP 1.4.7: Steady State Voltage}

Steady state voltage $\left(\mathrm{V}_{\mathrm{rms}}\right)$ will be measured at one-minute intervals at all generator and load interconnection points on a per phase basis. The steady state voltage should not exceed the ranges specified in Table A.1 using a 15-minute average of $\mathrm{V}_{\mathrm{rms}}$ for "greater than 5 minutes", a 5-minute average of $\mathrm{V}_{\mathrm{rms}}$ for "greater than 1 minute", and instantaneous measurements for "less than 1 minute", again on a per phase basis. These requirements will be relaxed during the initial startup phase of the microgrid (first five minutes after disconnect from grid operations). Base voltages for per-unit calculations will be specified by equipment nameplate and ratings at interconnection points, depending upon where the measurement device is located.

\section{A.1.4.5 MOP 1.4.8 - MOP 1.4.11: Voltage Imbalance}

Voltage imbalance, often referred to as phase voltage imbalance, is a measure of the inequality of Root Mean Square (RMS) line voltages on poly-phase systems. Large imbalances in the voltage between the three phases can lead to excessive heating in motor coils, leading to greater losses and possible motor damage. Voltage imbalance is defined as shown in equation (A.11):

$$
\begin{aligned}
\text { Voltage Imbalance } & =100 \% * \frac{\text { max deviation from average voltage }}{\text { average voltage }} \\
& =\frac{\max \left(V_{A}-V_{A V G}, V_{B}-V_{A V G}, V_{C}-V_{A V G}\right)}{\operatorname{average}\left(V_{A}, V_{B}, V_{C}\right)}
\end{aligned}
$$

Voltage imbalance is limited to less than 3\% by ANSI standards (NEMA MG-1 requires that motors not operate with a more than $5 \%$ imbalance). The Colorado Springs Utilities has more 
stringent standards that only allow $1 \%$ unbalance between phases and 3\% unbalance to ground. However, this is only for interconnected distributed generation resources and should not factor into the Phase 2 demonstrations.

$\mathrm{V}_{\text {rms }}$ will be measured at one-minute intervals at all generator and load interconnection points on a per phase basis. Voltage imbalance will then be calculated at one-minute intervals throughout the test. Voltage imbalance should not exceed 3\% during the test for more than a one-minute interval; 5\% will be acceptable for a single one-minute measurement. These requirements will be relaxed during the initial startup phase of the microgrid (first five minutes after disconnect from grid operations).

\section{A.2 MOE 2: Efficiency}

MOE 2 will address how efficiently SPIDERS uses the available resources during critical operations periods. MOE 2 will quantify the power produced by the diesel generators per unit fuel, as well as the losses incurred during the distribution and usage of the generated power. With information on the efficiency of the SPIDERS operations, estimates on runtime duration and deliverable power capabilities can be estimated based on available fuel stocks. In addition to these operations-centric impacts, information on the environmental impact of the SPIDERS operation mode will be obtained. Estimates of the $\mathrm{CO}_{2}$, NOx, SOx, and PM-10 emissions will be created.

\section{A.2.1 MOE 2.1: System Efficiency}

MOE 2.1 evaluates the effectiveness of the diesel backup generators while serving system loads during emergency operations. Through the addition of renewable generation and energy storage, operation of the diesel generators should decrease for the critical loads, or allow secondary loads to be served as well. Furthermore, increased distribution switch-gear should allow more effective dispatch of the generators available. Phase 2 testing is expected to evaluate the 1,250 kW, 1,000 $\mathrm{kW}$, and $900 \mathrm{~kW}$ diesel generators on the Fort Carson system. Specific manufacturer specifications and testing information is available for a $1,600 \mathrm{~kW}$ generator from Phase I. If equivalent information is not available for the Fort Carson generators, values for the 1,600 kW generator from the Phase I demonstration will be scaled and used, where appropriate.

For traditional operation estimates, all three generators only served as backup generators for their corresponding buildings. The estimate of which generator is running, and the duration of the operation, will be conducted using load measurements of the various buildings during SPIDERS operation.

Where appropriate, two values will be calculated for each metric within the generation fleet. One value will be a "total change" value, which will represent accumulated totals for the entire Phase 2 demonstration and may be negative numbers (due to the generators serving more load). The second value will be more of an "intensity" value (e.g.,Watts per gallon of fuel) to show that 
even though more load is being served by the generators, they may be operating more efficiently with this additional load.

\section{A.2.1.1 MOP 2.1.1: Diesel Generator Increased Efficiency}

Generator efficiency quantifies how well the generator produced power for the amount of fuel it consumed; specifically, the efficiency at the current operating point. With the flexibility of the SPIDERS framework and renewable generation, diesel generator operation during emergency operations can be better managed. Diesel generators can be operated closer to their peak efficiency output, rather than being severely oversized. For example, a 1,600 kW generator running at $1500 \mathrm{~kW}$ output produces electricity a lot more efficiently than the same generator only supplying $500 \mathrm{~kW}$. If the diesel generator is more efficiently dispatched, fuel stores can be used to a greater potential. The efficiency of the generators does not increase; it is an increase of efficiency due to a change in operating point.

Generator efficiency is calculated by:

1) Measure real power $\left(P_{G}(t)\right)$ and reactive power $\left(Q_{G}(t)\right)$ for each diesel generator for each measurement interval, $d t$.

2) Measure the fuel consumed by the generator $\left(f_{c o n}(t)\right)$ for the 1-day interval.

3) Measure real power, $P_{L}(t)$, and reactive power, $Q_{L}(t)$, for all building loads for each measurement interval, $d t$, during a normal operations time (grid-connected and nonSPIDERS operations).

4) Estimate the energy produced by the generator using equation (A.12):

$$
E_{\text {generated }}=\int \sqrt{P_{G}(t)^{2}+Q_{G}(t)^{2}} d t
$$

such that the integral is taken over the same 1-day time period as the fuel measurement interval (i.e., the limits of the integral are the time between the previous and current fuel consumption measurements).

5) Estimate the fuel efficiency $\eta_{S P I D E R S}$, for the generator using equation (A.13):

$$
\eta_{\text {SPIDERS }}=\frac{E_{\text {generated }}}{f_{\text {con }}(t)}
$$

Note: if fuel efficiency is required over multiple days, an average of individual day $\eta_{\text {SPIDERS }}$ is recommended over integrating the energy over the multiple day period.

6) Estimate the fuel efficiency during traditional operations, $\eta_{T R A D}$, using the assumption each generator is running full time on the building it is directly serving. The fuel efficiency calculation will be accomplished in the following steps: 
a. Determine building apparent load, $\left|S_{L}(t)\right|$ at each interval, $d t$, using equation (A.14):

$$
\left|S_{L}(t)\right|=\sqrt{P_{L}(t)^{2}+Q_{L}(t)^{2}}
$$

b. Utilize the building apparent load and the generator efficiencies associated with the generator to determine the estimated fuel consumption during "normal" operation, $f_{\text {con_trad }}(t)$.

c. Compute the expected energy "generated" under traditional operation, $E_{\text {gen_trad, }}$ using equation (A.15):

$$
E_{\text {gen_load }}=\int\left|S_{L}(t)\right| d t
$$

such that the integration occurs over the full SPIDERS operation period for the appropriate times the generator is running.

d. Estimate the fuel efficiency of traditional operation, $\eta_{T R A D}$, using equation (A.16):

$$
\eta_{T R A D}=\frac{E_{\text {gen_trad }}}{f_{\text {con_trad }}(t)}
$$

7) Calculate the increased efficiency percentage using equation (A.17):

$$
\eta_{\text {increase }}=\frac{\eta_{\text {SPIDERS }}-\eta_{T R A D}}{\eta_{T R A D}} \times 100
$$

Note: $\eta_{\text {increase }}$ will be negative if the diesel generator operated in a less efficient manner during the SPIDERS test.

\section{A.2.1.2 MOP 2.1.2: Diesel Generator Reduced Run Time}

Reduced run time quantifies how much less time the diesel generator was required to run under emergency operations governed by SPIDERS. This metric indicates less wear and tear on the machines (so extended maintenance cycles), as well as a coarse indication of reduced fuel use and environmental emissions. Reduced run time is calculated by:

1) Measure real power $(P(t))$ for the diesel generators for each measurement interval, $d t$.

2) Measure real power, $P_{L}(t)$, for all buildings for each measurement interval, $d t$, during a normal operations time (grid-connected and non-SPIDERS operations).

3) Estimate the run time, $R T_{\text {SPIDERS }}$, by summing all $d t$ values for which $P(t)$ is non-zero. This is accomplished using equation (A.18): 


$$
R T_{\text {SPIDERS }}=\sum d t \in\{P(t) \neq 0\}
$$

4) Estimate the run time of the diesel generator during traditional operations, $R T_{T R A D}$.by accumulating $d t$ values for which $P_{L}(t)$ is non-zero. Accumulate only over the intervals this generator would be expected to run, based on the assumptions outlined in the A.2.1 overview. The run time of traditional operations can be computed using equation (A.19):

$$
R T_{\text {TRAD }}=\sum d t \in\left\{\left(P_{L}(t) \neq 0\right)\right\}
$$

such that the $d t$ intervals represent when the generators would be running.

5) Calculate the reduced run time using equation (A.20):

$$
\text { Reduced Run Time }=R T_{\text {TRAD }}-R T_{\text {SPIDERS }}
$$

\section{A.2.1.3 MOP 2.1.3: Diesel Generator Reduced Total $\mathrm{CO}_{2}$}

Reduced $\mathrm{CO}_{2}$ emissions quantify the reduced impact of the diesel generator when operating under the SPIDERS scheme. Under emergency operations governed by the SPIDERS scheme, the generator may be operating more efficiently, or for fewer hours. This should reduce the $\mathrm{CO}_{2}$ impact of this generator. Reduced $\mathrm{CO}_{2}$ will be computed as:

1) Measure real power $(P(t))$ and reactive power $(Q(t))$ for the diesel generator for each measurement interval, $d t$.

2) Measure real power, $P_{L}(t)$, for all buildings for each measurement interval, $d t$, during a normal operations time (grid-connected and non-SPIDERS operations).

3) Calculate the estimated $\mathrm{CO}_{2}$ emissions for the generator under SPIDERS operation, $\mathrm{CO}_{2 \text { SPIDERS }}$, using the following procedure:

a. Extrapolate the expected $\mathrm{CO}_{2}$ emission rate, $\mathrm{CO}_{2 S P I D E R S_{-} H R}$, in $\mathrm{lbm} / \mathrm{hr}$., based on the real power output of the generator. Table A.3 below is excerpted from a Caterpillar datasheet for a $1.6 \mathrm{MW}$ diesel generator.

Table A.3: Caterpillar 1.6 MW CO 2 Diesel Generator Emission Values

\begin{tabular}{|c|c|}
\hline $\begin{array}{c}\text { Generator } \\
\text { Output }(\mathrm{kW})\end{array}$ & $\begin{array}{c}\mathrm{CO}_{2} \\
(\mathrm{lbm} / \mathrm{hr} .)\end{array}$ \\
\hline 1,600 & $2,494.1$ \\
\hline 1,200 & $1,926.0$ \\
\hline 800 & $1,356.3$ \\
\hline 400 & 801.4 \\
\hline 160 & 467.4 \\
\hline
\end{tabular}

b. Weight the hourly amounts by the measurement interval, $d t$. 


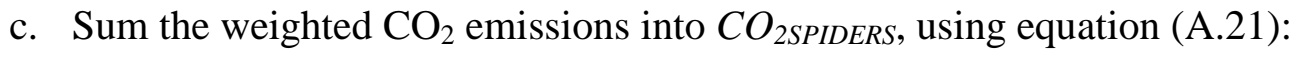

$$
C O_{2 \text { SPIDERS }}=\sum_{i \subset t} \mathrm{CO}_{\text {SSPIDERS }_{-} H R i} d t_{i}
$$

4) Calculate the estimated $\mathrm{CO}_{2}$ output for traditional operations, $\mathrm{CO}_{2 T R A D}$ :

a. Determine the expected real power output of the generator from the building load, $P_{L}(t)$. Only consider intervals where this generator would be running normally, per overall guidance outlined in the A.2.1 overview.

b. Extrapolate the estimated interval $\mathrm{CO}_{2}$ output, $\mathrm{CO}_{2 T R A D_{-} H R}$, using the table in step $3 b$ above.

c. Weight the hourly amounts by the measurement interval, $d t$.

d. Sum the weighted $\mathrm{CO}_{2}$ emissions into $\mathrm{CO}_{2 T R A D}$, using equation (A.22):

$$
C O_{2 T R A D}=\sum_{i \subset t} C O_{2 T R A D_{-} H R i} d t_{i}
$$

5) Calculate the reduced $\mathrm{CO}_{2}$ emissions using equation (A.23):

$$
\text { Reduced } \mathrm{CO}_{2}=\mathrm{CO}_{2 \text { TRAD }}-\mathrm{CO}_{2 \text { SPIDERS }}
$$

\section{A.2.1.4 MOP 2.1.4: Diesel Generator Reduced Average $\mathrm{CO}_{2}$ Intensity}

Under the operating guidelines for Phase 2, some of the generators will likely be running the full time and serving more load than during traditional islanded operations. As a result, the total $\mathrm{CO}_{2}$ output will probably increase. However, the generator may be operating at a more efficient set point, thus providing less $\mathrm{CO}_{2}$ output per unit electricity produced. To quantify this impact, the average $\mathrm{CO}_{2}$ intensity will be examined. Reduced Average $\mathrm{CO}_{2}$ Intensity will be computed as:

1) Measure real power $(P(t))$ and reactive power $(Q(t))$ for the diesel generator for each measurement interval, $d t$.

2) Measure real power, $P_{L}(t)$, for the buildings for each measurement interval, $d t$, during a normal operations time (grid-connected and non-SPIDERS operations).

3) Calculate the estimated average $\mathrm{CO}_{2}$ intensity for the generator under SPIDERS operation, $\mathrm{CO}_{\text {2SPIDERS-Intesnity, using the following procedure: }}$

a. Extrapolate the expected $\mathrm{CO}_{2}$ emission rate, $\mathrm{CO}_{2 S P I D E R S_{-} H R}$, in $\mathrm{lbm} / \mathrm{hr}$., based on the real power output of the generator. If no generator-specific source is available, utilize Table A. 3 above for these calculations 
b. Weight the hourly amounts by the measurement interval, $d t$.

c. Calculate the energy for each measurement interval, $d t$, using equation (A.24):

$$
E_{\text {SPIDERS }}(t)=P(t) d t
$$

d. Calculate the $\mathrm{CO}_{2}$ intensity for each measurement interval, $d t$, using equation (A.25):

$$
C O_{\text {2SPIDERSPerDT }}(t)=\frac{\text { CO }_{\text {ISPIDERS }_{-} H R}(t)}{E_{\text {SPIDERS }_{-}(t)}}
$$

e. Calculate the average $\mathrm{CO}_{2}$ intensity using equation (A.26):

$$
C O_{\text {2SPIDERS-Intensity }}=\frac{\sum_{t} C O_{2 S P I D E R S P e r D T}(t)}{}
$$

4) Calculate the estimated average $\mathrm{CO}_{2}$ intensity for traditional operations, $C O_{2 T R A D-I n t e n s i t y}$ :

a. Determine the expected real power output of the generator from the building load, $P_{L}(t)$. Only consider intervals where this generator would be running normally, per overall guidance outlined in the A.2.1 overview.

b. Extrapolate the estimated interval $\mathrm{CO}_{2}$ output, $\mathrm{CO}_{2 T R A D_{-} H R}$, using the table in step 3a above.

c. Weight the hourly amounts by the measurement interval, $d t$.

d. Calculate the energy for each measurement interval, $d t$, using equation (A.27):

$$
E_{T R A D}(t)=P_{L}(t) d t
$$

e. Calculate the $\mathrm{CO}_{2}$ intensity for each measurement interval, $d t$, using equation (A.28):

$$
C O_{2 T R A D p e r D T}(t)=\frac{C O_{2 T R A D_{-} H R}(t)}{E_{\text {TRAD }}(t)}
$$

f. Calculate the average $\mathrm{CO}_{2}$ intensity using equation (A.29):

$$
C O_{2 T R A D-\text { Intensity }}=\frac{\sum_{t} C O_{2 T R A D p e r D T}(t)}{\sum_{t} d t}
$$

5) Calculate the reduced average $\mathrm{CO}_{2}$ intensity using equation (A.30): 
Reduced $\mathrm{CO}_{2}$ Intensity $=\mathrm{CO}_{2 \text { TRAD-Intensity }}-\mathrm{CO}_{2 \text { SPIDERS-Intensity }}$

\section{A.2.1.5 MOP 2.1.5: Diesel Generator Reduced Total NOx}

Reduced NOx emissions quantify the reduced impact of the diesel generator when operating under the SPIDERS scheme. Under emergency operations governed by the SPIDERS scheme, the generator may be operating more efficiently, or for fewer hours. This should reduce the NOx impact of this generator. Reduced NOx will be computed as:

1) Measure real power $(P(t))$ and reactive power $(Q(t))$ for the diesel generator for each measurement interval, $d t$.

2) Measure real power, $P_{L}(t)$, for the buildings for each measurement interval, $d t$, during a normal operations time (grid-connected and non-SPIDERS operations).

3) Calculate the estimated NOx emissions for the generator under SPIDERS operation, $N O x_{\text {SPIDERS }}$, using the following procedure:

a. Extrapolate the expected NOx emission rate, $N O x_{S P I D E R S \_H R}$, in $\mathrm{lbm} / \mathrm{hr}$., based on the real power output of the generator. Table A.4 below is excerpted from a Caterpillar datasheet for a $1.6 \mathrm{MW}$ diesel generator.

Table A.4: Caterpillar 1.6 MW NOx Diesel Generator Emission Values

\begin{tabular}{|c|c|}
\hline $\begin{array}{c}\text { Generator } \\
\text { Output }(\mathrm{kW})\end{array}$ & $\begin{array}{c}\text { NOx } \\
(\mathrm{lbm} / \mathrm{hr} .)\end{array}$ \\
\hline 1,600 & 53.93 \\
\hline 1,200 & 48.46 \\
\hline 800 & 34.67 \\
\hline 400 & 17.6 \\
\hline 160 & 9.84 \\
\hline
\end{tabular}

b. Weight the hourly amounts by the measurement interval, $d t$.

c. Sum the weighted NOx emissions into $N O x_{\text {SPIDERS }}$, using equation (A.31):

$$
N O x_{\text {SPIDERS }}=\sum_{i \subset t} N O x_{\text {SPIDERS_HRi }_{-}} d t_{i}
$$

4) Calculate the estimated NOx output for traditional operations, $N O x_{T R A D}$ :

a. Determine the expected real power output of the generator from the building load, $P_{L}(t)$. Only consider intervals where this generator would be running normally, per overall guidance outlined in the A.2.1 overview.

b. Extrapolate the estimated interval NOx output, $N O x_{T R A D_{-} H R}$, using the table in step 
3b above.

c. Weight the hourly amounts by the measurement interval, $d t$.

d. Sum the weighted NOx emissions into $N O x_{T R A D}$, using equation (A.32):

$$
N O x_{T R A D}=\sum_{i \subset t} N O x_{T R A D_{-} H R i} d t_{i}
$$

5) Calculate the reduced NOx emissions using equation (A.33):

$$
\text { Reduced NOx }=N O x_{T R A D}-N O x_{\text {SPIDERS }}
$$

\section{A.2.1.6 MOP 2.1.6: Diesel Generator Reduced Average NOx Intensity}

Under the operating guidelines for Phase 2, the generators will likely be running the full time and serving more load than during traditional islanded operations. As a result, the total NOx output will probably increase. However, the generator may be operating at a more efficient set point, thus providing less NOx output per unit electricity produced. To quantify this impact, the average NOx intensity will be examined. Reduced Average NOx Intensity will be computed as:

1) Measure real power $(P(t))$ and reactive power $(Q(t))$ for the diesel generator for each measurement interval, $d t$.

2) Measure real power, $P_{L}(t)$, for the buildings for each measurement interval, $d t$, during a normal operations time (grid-connected and non-SPIDERS operations).

3) Calculate the estimated average NOx intensity for the generator under SPIDERS operation, NOx $x_{\text {SPIDERS-Intesnity, }}$ using the following procedure:

a. Extrapolate the expected NOx emission rate, NOx $x_{S P I D E R S \_H R}$, in $\mathrm{lbm} / \mathrm{hr}$., based on the real power output of the generator. If no generator-specific source is available, utilize Table A.4 above for these calculations

b. Weight the hourly amounts by the measurement interval, $d t$.

c. Calculate the energy for each measurement interval, $d t$, using equation (A.34):

$$
E_{\text {SPIDERS }}(t)=P(t) d t
$$

d. Calculate the NOx intensity for each measurement interval, $d t$, using equation (A.35): 


$$
N O x_{\text {SPIDERSperDT }}(t)=\frac{N O x_{\text {SPIDERS_HR }_{-} H}(t)}{E_{\text {SPIDERS }(t)}}
$$

e. Calculate the average NOx intensity using equation (A.36):

$$
N O x_{\text {SPIDERS-Intensity }}=\frac{\sum_{t} N O x_{\text {SPIDERSPerDT }}(t)}{\sum_{t} d t}
$$

4) Calculate the estimated average NOx intensity for traditional operations, NOx $x_{T R A D-I n t e n s i t y}$ :

a. Determine the expected real power output of the generator from the building load, $P_{L}(t)$. Only consider intervals where this generator would be running normally, per overall guidance outlined in the A.2.1 overview.

b. Extrapolate the estimated interval NOx output, $N O x_{T R A D \_H R}$, using the table in step 3a above.

c. Weight the hourly amounts by the measurement interval, $d t$.

d. Calculate the energy for each measurement interval, $d t$, using equation (A.37):

$$
E_{T R A D}(t)=P_{L}(t) d t
$$

e. Calculate the NOx intensity for each measurement interval, $d t$, using equation (A.38):

$$
N O x_{\text {TRADperDT }}(t)=\frac{N O x_{T R A D_{-} H R}(t)}{E_{T R A D}(t)}
$$

f. Calculate the average NOx intensity using equation (A.39):

$$
N O x_{T R A D-\text { Intensity }}=\frac{\sum_{t} N O x_{\text {TRADperDT }}(t)}{\sum_{t} d t}
$$

5) Calculate the reduced average NOx intensity using equation (A.40):

$$
\text { Reduced NOx Intensity }=N O x_{\text {TRAD-Intensity }}-N O x_{\text {SPIDERS-Intensity }}
$$

\section{A.2.1.7 MOP 2.1.7: Diesel Generator Reduced Total SOx}

Reduced SOx emissions quantify the reduced impact of the diesel generator when operating under the SPIDERS scheme. Under emergency operations governed by the SPIDERS scheme, 
the generator may be operating more efficiently, or for fewer hours. This should reduce the SOx impact of this generator. Reduced SOx will be computed as:

1) Measure real power $(P(t))$ and reactive power $(Q(t))$ for the diesel generator for each measurement interval, $d t$.

2) Measure real power, $P_{L}(t)$, for building load for each measurement interval, $d t$, during a normal operations time (grid-connected and non-SPIDERS operations).

3) Calculate the estimated SOx emissions for the generator under SPIDERS operation, $S O x_{S P I D E R S}$, using the following procedure:

a. Extrapolate the expected SOx emission rate, SOx $x_{\text {SPIDERS_HR }}$, in $\mathrm{lbm} / \mathrm{hr}$., based on the real power output of the generator. Table A.5 below is excerpted from a Caterpillar datasheet for a $1.6 \mathrm{MW}$ diesel generator.

Table A.5: Caterpillar 1.6 MW SOx Diesel Generator Emission Values

\begin{tabular}{|c|c|}
\hline $\begin{array}{c}\text { Generator } \\
\text { Output }(\mathrm{kW})\end{array}$ & $\begin{array}{c}\text { SOx } \\
(\mathrm{lbm} / \mathrm{hr} .)\end{array}$ \\
\hline 1,600 & 3.15 \\
\hline 1,200 & 2.44 \\
\hline 800 & 1.71 \\
\hline 400 & 1.01 \\
\hline 160 & 0.6 \\
\hline
\end{tabular}

b. Weight the hourly amounts by the measurement interval, $d t$.

c. Sum the weighted SOx emissions into $S O x_{\text {SPIDERS }}$, using equation (A.41):

$$
S O x_{\text {SPIDERS }}=\sum_{i \subset t} S O x_{\text {SPIDERS_HRi }} d t_{i}
$$

4) Calculate the estimated SOx output for traditional operations, $S O x_{T R A D}$ :

a. Determine the expected real power output of the generator from the building load, $P_{L}(t)$. Only consider intervals where this generator would be running normally, per overall guidance outlined in the A.2.1 overview.

b. Extrapolate the estimated interval SOx output, $S O x_{T R A D_{-} H R}$, using the table in step $3 b$ above.

c. Weight the hourly amounts by the measurement interval, $d t$.

d. Sum the weighted SOx emissions into $S O x_{T R A D}$, using equation (A.42): 


$$
S O x_{T R A D}=\sum_{i \subset t} S O x_{T R A D_{-} H R i} d t_{i}
$$

5) Calculate the reduced SOx emissions using equation (A.43):

$$
\text { Reduced SOx }=S O x_{\text {TRAD }}-S O x_{\text {SPIDERS }}
$$

\section{A.2.1.8 MOP 2.1.8: Diesel Generator Reduced Average SOx Intensity}

Under the operating guidelines for Phase 2, the generators will likely be running the full time and serving more load than during traditional islanded operations. As a result, the total SOx output will probably increase. However, the generator may be operating at a more efficient set point, thus providing less SOx output per unit electricity produced. To quantify this impact, the average SOx intensity will be examined. Reduced Average SOx Intensity will be computed as:

1) Measure real power $(P(t))$ and reactive power $(Q(t))$ for the diesel generator for each measurement interval, $d t$.

2) Measure real power, $P_{L}(t)$, for the building loads for each measurement interval, $d t$, during a normal operations time (grid-connected and non-SPIDERS operations).

3) Calculate the estimated average SOx intensity for the generator under SPIDERS operation,




the real power output of the generator. If no generator-specific source is available, utilize Table A.5 above for these calculations

b. Weight the hourly amounts by the measurement interval, $d t$.

c. Calculate the energy for each measurement interval, $d t$, using equation (A.44):

$$
E_{\text {SPIDERS }}(t)=P(t) d t
$$

d. Calculate the SOx intensity for each measurement interval, $d t$, using equation (A.45):

$$
\operatorname{SOx}_{\text {SPIDERSPerDT }}(t)=\frac{\operatorname{SOx}_{\text {SPIDERS_HR }_{-}}(t)}{E_{\text {SPIDERS }}(t)}
$$

e. Calculate the average SOx intensity using equation (A.46): 


$$
S O x_{\text {SPIDERS-Intensity }}=\frac{\sum_{t} S O x_{\text {SPIDERSPerDT }}(t)}{\sum_{t} d t}
$$

4) Calculate the estimated average SOx intensity for traditional operations, $S O x_{T R A D-I n t e n s i t y}$ :

a. Determine the expected real power output of the generator from the building load, $P_{L}(t)$. Only consider intervals where this generator would be running normally, per overall guidance outlined in the A.2.1 overview.

b. Extrapolate the estimated interval SOx output, $S O x_{T R A D_{-} H R}$, using the table in step 3a above.

c. Weight the hourly amounts by the measurement interval, $d t$.

d. Calculate the energy for each measurement interval, $d t$, using equation (A.47):

$$
E_{\text {TRAD }}(t)=P_{L}(t) d t
$$

e. Calculate the SOx intensity for each measurement interval, $d t$, using equation (A.48):

$$
S O x_{T R A D P e r D T}(t)=\frac{S O x_{T R A D_{-} H R}(t)}{E_{\text {TRAD }}(t)}
$$

f. Calculate the average SOx intensity using equation (A.49):

$$
S O x_{\text {TRAD-Intensity }}=\frac{\sum_{t} S O x_{\text {TRADperDT }}(t)}{\sum_{t} d t}
$$

5) Calculate the reduced average SOx intensity using equation (A.50):

$$
\text { Reduced SOx Intensity }=S O x_{\text {TRAD-Intensity }}-S O x_{\text {SPIDERS-Intensity }}
$$

\section{A.2.1.9 MOP 2.1.9: Diesel Generator Reduced Total PM-10}

Reduced PM-10 emissions quantify the reduced impact of the diesel generator when operating under the SPIDERS scheme. Under emergency operations governed by the SPIDERS scheme, the generator may be operating more efficiently, or for fewer hours. This should reduce the PM10 impact of this generator. Reduced PM-10 will be computed as:

1) Measure real power $(P(t))$ and reactive power $(Q(t))$ for the diesel generator for each measurement interval, $d t$. 
2) Measure real power, $P_{L}(t)$, for building load for each measurement interval, $d t$, during a normal operations time (grid-connected and non-SPIDERS operations).

3) Calculate the estimated PM-10 emissions for the generator under SPIDERS operation, $P M-10_{\text {SPIDERS }}$, using the following procedure:

a. Extrapolate the expected PM-10 emission rate, PM-10 $10_{\text {SPIDERS_HR }}$, in $\mathrm{lbm} / \mathrm{hr}$., based on the real power output of the generator. Table A.6 below is excerpted from a Caterpillar datasheet for a 1.6 MW diesel generator.

Table A.6: Caterpillar 1.6 MW PM-10 Diesel Generator Emission Values

\begin{tabular}{|c|c|}
\hline $\begin{array}{c}\text { Generator } \\
\text { Output }(\mathrm{kW})\end{array}$ & $\begin{array}{c}\text { PM-10 } \\
(\mathrm{lbm} / \mathrm{hr} .)\end{array}$ \\
\hline 1,600 & 0.76 \\
\hline 1,200 & 0.49 \\
\hline 800 & 0.44 \\
\hline 400 & 0.40 \\
\hline 160 & 0.52 \\
\hline
\end{tabular}

b. Weight the hourly amounts by the measurement interval, $d t$.

c. Sum the weighted PM-10 emissions into PM10

$$
P M 10_{\text {SPIDERS }}=\sum_{i \subset t} P M 10_{\text {SPIDERS_HRi }} d t_{i}
$$

4) Calculate the estimated PM-10 output for traditional operations, $P M 10_{T R A D}$ :

a. Determine the expected real power output of the generator from the building load, $P_{L}(t)$. Only consider intervals where this generator would be running normally, per overall guidance outlined in the A.2.1 overview.

b. Extrapolate the estimated interval PM-10 output, $P M 10_{T R A D \_H R}$, using the table in step $3 b$ above.

c. Weight the hourly amounts by the measurement interval, $d t$.

d. Sum the weighted PM-10 emissions into PM10 ${ }_{T R A D}$, using equation (A.52):

$$
P M 10_{T R A D}=\sum_{i \subset t} P M 10_{T R A D_{-} H R i} d t_{i}
$$

5) Calculate the reduced PM-10 emissions using equation (A.53):

$$
\text { Reduced PM10 }=P M 10_{\text {TRAD }}-P M 10_{\text {SPIDERS }}
$$




\section{A.2.1.10 MOP 2.1.10: Diesel Generator Reduced Average PM-10 Intensity}

Under the operating guidelines for Phase 2, the generators will likely be running the full time and serving more load than during traditional islanded operations. As a result, the total PM-10 output will probably increase. However, the generator may be operating at a more efficient set point, thus providing less PM-10 output per unit electricity produced. To quantify this impact, the average PM-10 intensity will be examined. Reduced Average PM-10 Intensity will be computed as:

1) Measure real power $(P(t))$ and reactive power $(Q(t))$ for the diesel generator for each measurement interval, $d t$.

2) Measure real power, $P_{L}(t)$, for building loads for each measurement interval, $d t$, during a normal operations time (grid-connected and non-SPIDERS operations).

3) Calculate the estimated average PM-10 intensity for the generator under SPIDERS operation, PM10 SPIDERS-Intesnity, using the following procedure:

a. Extrapolate the expected PM-10 emission rate, $P M 10_{S P I D E R S_{-} H R}$, in $1 \mathrm{bm} / \mathrm{hr}$., based on the real power output of the generator. If no generator-specific source is available, utilize Table A.6 above for these calculations

b. Weight the hourly amounts by the measurement interval, $d t$.

c. Calculate the energy for each measurement interval, $d t$, using equation (A.54):

$$
E_{\text {SPIDERS }}(t)=P(t) d t
$$

d. Calculate the PM-10 intensity for each measurement interval, $d t$, using equation (A.55):

$$
P M 10_{\text {SPIDERSperDT }}(t)=\frac{P M 10_{\text {SPIDERS_HR }_{-}(t)}}{E_{\text {SPIDERS }(t)}}
$$

e. Calculate the average PM-10 intensity using equation (A.56):

$$
P M 10_{\text {SPIDERS-Intensity }}=\frac{\sum_{t} P M 10_{\text {SPIDERSperDT }}(t)}{\sum_{t} d t}
$$

4) Calculate the estimated average PM-10 intensity for traditional operations, PM10 TRAD-Intensity:

a. Determine the expected real power output of the generator from the building load, $P_{L}(t)$. Only consider intervals where this generator would be running normally, 
per overall guidance outlined in the A.2.1 overview.

b. Extrapolate the estimated interval PM-10 output, $P M 10_{T R A D \_H R}$, using the table in step 3 a above.

c. Weight the hourly amounts by the measurement interval, $d t$.

d. Calculate the energy for each measurement interval, $d t$, using equation (A.57):

$$
E_{T R A D}(t)=P_{L}(t) d t
$$

e. Calculate the PM-10 intensity for each measurement interval, $d t$, using equation (A.58):

$$
P M 10_{\text {TRADperDT }}(t)=\frac{P M 10_{T_{R A D_{-} H R}}(t)}{E_{\text {TRAD }}(t)}
$$

f. Calculate the average PM-10 intensity using equation (A.59):

$$
P M 10_{\text {TRAD-Intensity }}=\frac{\sum_{t} P M 10_{\text {TRADperDT }}(t)}{\sum_{t} d t}
$$

5) Calculate the reduced average PM-10 intensity using equation (A.60):

$$
\text { Reduced PM10Intensity }=P M 10_{2 T R A D-\text { Intensity }}-P M 10_{2 S P I D E R S-I n t e n s i t y}
$$

\section{A.2.1.11 MOP 2.1.11: System Real Losses (kWh)}

The purpose of this metric is to observe the real losses accumulated during microgrid operation in the transport of energy from the generation source to the load center. Losses will be calculated as the difference between the generation and the load of the system. For the purposes of this metric, the electric vehicles and EVSE-based contributions will lumped in with the load of the system, despite being dispatched as part of both the load and generation portions of the system. It is useful to note that while a number can be produced, it isn't necessarily a fair comparison. While additional losses are accrued by having the distribution network interconnecting the different generators, it is also allowing the introduction of the photovoltaic generation. Compared to traditional operation, this was not present and actually represents a negative loss scenario. A quantitative value can be calculated using the following procedure. However, qualitative notes about the inclusion of renewables should be noted.

1) Determine the real power $\left(P_{G e n}(t)\right)$ for the generation sources on the microgrid for each measurement interval, $d t$, during SPIDERS operation. 
a. Measure real power $\left(P_{1250}(t)\right)$ for the $1250 \mathrm{~kW}$ diesel generator for each measurement interval, $d t$.

b. Measure real power $\left(P_{1000}(t)\right)$ for the $1000 \mathrm{~kW}$ diesel generator for each measurement interval, $d t$.

c. Measure real power $\left(P_{900}(t)\right)$ for the $900 \mathrm{~kW}$ diesel generator for each measurement interval, $d t$.

d. Measure real power $\left(P_{\text {Solar }}(t)\right)$ for the solar array at Fort Carson for each measurement interval, $d t$. All individual inverters will be lumped into one term.

e. Accumulate the real power for each interval using equation (A.61)

$$
P_{\text {Gen }}(t)=P_{1250}(t)+P_{1000}(t)+P_{900}(t)+P_{\text {Solar }}(t)
$$

2) Determine the real power $\left(P_{\text {SPIDERSLad }}(t)\right)$ for load sources on the microgrid for each measurement interval, $d t$, during the same SPIDERS interval at step 1.

3) Determine the real power losses on the system, $P_{\text {LOSSSPIDERS }}(t)$, for each measurement interval during the SPIDERS test using equation (A.62):

$$
P_{\text {LOSSSPIDERS }}(t)=P_{\text {Gen }}(t)-P_{\text {SPIDERSLoad }}(t)
$$

4) Calculate the system real losses during the SPIDERS interval using (A.63):

$$
E_{\text {LOSSSPIDERS }}=\int P_{\text {LOSSSPIDERS }}(t) d t
$$

5) Repeat step 2 for normal operations time to produce $P_{\text {NORMLOAD }}(t)$.

6) Determine the input power to the system during normal operations, $P_{\text {GENNORM }}(t)$, for each measurement interval, $d t$.

a. Determine the real power flowing from the Minnick substation $\left(P_{\text {MINNORM }}(t)\right)$ during normal operations, for each measurement interval, $d t$.

b. Measure real power $\left(P_{\text {SolarNorm }}(t)\right)$ for the solar array at Fort Carson for each measurement interval, $d t$. All individual inverters will be lumped into one term.

c. Accumuate the normal operation input power using (A.64):

$$
P_{\text {GENNORM }}(t)=P_{\text {MINNORM }}(t)+P_{\text {SolarNorm }}(t)
$$

7) Determine the real power losses on the system, $P_{\operatorname{LOSNORM}}(t)$, for each measurement interval during a normal operations period using equation (A.65):

$$
P_{\text {LOSSNORM }}(t)=P_{\text {GENNORM }}(t)-P_{\text {NORMLoad }}(t)
$$

8) Calculate the system real losses during the normal operation interval using (A.66): 


$$
E_{\text {LOSSNORM }}=\int P_{\text {LOSSNORM }}(t) d t
$$

9) Compute the difference in real power losses using (A.67):

$$
E_{\text {LOSSCHANGE }}=E_{\text {LOSSNORM }}-E_{\text {LOSSSPIDERS }}
$$

Note that to compare the two terms fairly, if the "normal operations" interval was not equal to the SPIDERS operation interval, it should scaled appropriately so $E_{\text {LOSSNORM }}$ and $E_{\text {LOSSSPIDERS }}$ represent an identical duration of operation.

\section{A.2.1.12 MOP 2.2.2: System Reactive Losses (kVARh)}

The purpose of this metric is to observe the reactive losses accumulated during microgrid operation in the transport of energy from the generation source to the load center. Losses will be calculated as the difference between the generation and the load of the system. For the purposes of this metric, the electric vehicles and EVSE-based contributions will lumped in with the load of the system, despite being dispatched as part of both the load and generation portions of the system.

It is useful to again note that while a number can be produced, it isn't necessarily a fair comparison. While additional losses are accrued by having the distribution network interconnecting the different generators, it is also allowing the introduction of the photovoltaic generation. Compared to traditional operation, this was not present and actually represents a negative loss scenario. A quantitative value can be calculated using the following procedure. However, qualitative notes about the inclusion of renewables should be noted.

1) Determine the reactive power $\left(Q_{G e n}(t)\right)$ for the generation sources on the microgrid for each measurement interval, $d t$, during SPIDERS operation.

a. Measure reactive power $\left(Q_{1250}(t)\right)$ for the $1250 \mathrm{~kW}$ diesel generator for each measurement interval, $d t$.

b. Measure reactive power $\left(Q_{1000}(t)\right)$ for the $1000 \mathrm{~kW}$ diesel generator for each measurement interval, $d t$.

c. Measure reactive power $\left(Q_{900}(t)\right)$ for the $900 \mathrm{~kW}$ diesel generator for each measurement interval, $d t$.

d. Measure reactive power $\left(Q_{\text {Solar }}(t)\right)$ for the solar array at Fort Carson for each measurement interval, $d t$. All individual inverters will be lumped into one term.

e. Accumulate the reactive power for each interval using equation (A.68)

$$
Q_{\text {Gen }}(t)=Q_{1250}(t)+Q_{1000}(t)+Q_{900}(t)+Q_{\text {Solar }}(t)
$$

2) Determine the reactive power $\left(Q_{\text {SPIDERSLoad }}(t)\right)$ for load sources on the microgrid for each 
measurement interval, $d t$, during the same SPIDERS interval at step 1.

3) Determine the reactive power losses on the system, $Q_{\text {LOSSSPIDERS }}(t)$, for each measurement interval during the SPIDERS test using equation (A.69):

$$
Q_{\text {LOSSSPIDERS }}(t)=Q_{\text {Gen }}(t)-Q_{\text {SPIDERSLoad }}(t)
$$

4) Calculate the system reactive losses during the SPIDERS interval using (A.70):

$$
Q_{\text {LOSSSPIDERS }}=\int Q_{\text {LOSSSPIDERS }}(t) d t
$$

5) Repeat step 2 for normal operations time to produce $Q_{N O R M L O A D}(t)$.

6) Determine the input reactive power to the system during normal operations, $Q_{G E N N O R M}(t)$, for each measurement interval, $d t$.

a. Determine the reactive power flowing from the Minnick substation $\left(Q_{\text {MINNORM }}(t)\right)$ during normal operations, for each measurement interval, $d b$.

b. Measure reactive power $\left(Q_{\text {SolarNorm }}(t)\right)$ for the solar array at Fort Carson for each measurement interval, $d t$. All individual inverters will be lumped into one term.

c. Accumulate the normal operation input reactive power using (A.71):

$$
Q_{\text {GENNORM }}(t)=Q_{\text {MINNORM }}(t)+Q_{\text {SolarNorm }}(t)
$$

7) Determine the reactive power losses on the system, $Q_{\operatorname{LOSSNORM}}(t)$, for each measurement interval during a normal operations period using equation (A.72):

$$
Q_{\text {LOSSNORM }}(t)=Q_{\text {GENNORM }}(t)-Q_{\text {NORMLoad }}(t)
$$

8) Calculate the system reactive losses during the normal operation interval using (A.73):

$$
E_{\text {LOSSNORM }}=\int Q_{\text {LOSSNORM }}(t) d t
$$

9) Compute the difference in reactive power losses using (A.74):

$$
E_{\text {LOSSCHANGE }}=E_{\text {LOSSNORM }}-E_{\text {LOSSSPIDERS }}
$$

Note that to compare the two terms fairly, if the "normal operations" interval was not equal to the SPIDERS operation interval, it should scaled appropriately so $E_{L O S S N O R M}$ and $E_{L O S S S P I D E R S}$ represent an identical duration of operation. 


\section{A.2.1.13 MOP 2.2.3: System Real Losses (\%)}

This metric evaluates the "operational efficiency" of the system. The amount of real power losses during the peak demand time (determined by maximal generator output) will be calculated using the following procedure:

1) Determine the real power $\left(P_{G e n}(t)\right)$ for the generation sources on the microgrid for each measurement interval, $d t$, during SPIDERS operation.

a. Measure real power $\left(P_{1250}(t)\right)$ for the $1250 \mathrm{~kW}$ diesel generator for each measurement interval, $d t$.

b. Measure real power $\left(P_{1000}(t)\right)$ for the $1000 \mathrm{~kW}$ diesel generator for each measurement interval, $d t$.

c. Measure real power $\left(P_{900}(t)\right)$ for the $900 \mathrm{~kW}$ diesel generator for each measurement interval, $d t$.

d. Measure real power $\left(P_{\text {Solar }}(t)\right)$ for the solar array at Fort Carson for each measurement interval, $d t$. All individual inverters will be lumped into one term.

e. Accumulate the real power for each interval using equation (A.75):

$$
P_{\text {Gen }}(t)=P_{1250}(t)+P_{1000}(t)+P_{900}(t)+P_{\text {Solar }}(t)
$$

2) Find the maximum output value interval, $t_{\max }$, of $P_{G e n}(t)$.

3) Determine the real power for load sources on the microgrid at the peak demand time, $t_{\max }$.

4) Accumulate the load real power for $t_{\max }$.

5) Determine the real power loss percentage on the system during SPIDERS operation using equation (A.76):

$$
P_{\text {LOSSPERCSPIDERS }}=\frac{P_{G e n}\left(t_{\max }\right)-P_{\text {LOADMAX }}}{P_{G e n}\left(t_{\max }\right)} \times 100
$$

6) Estimate the losses during "normal' operations.

\section{A.2.1.14 MOP 2.2.4: System Reactive Losses (\%)}

This metric evaluates the "operational efficiency" of the system. The amount of reactive power losses during the peak real-power demand time (determined by maximal generator output) will be calculated using the following procedure:

1) Determine the real power $\left(P_{G e n}(t)\right)$ for the generation sources on the microgrid for each measurement interval, $d t$, during SPIDERS operation. 
a. Measure real power $\left(P_{1250}(t)\right)$ for the $1250 \mathrm{~kW}$ diesel generator for each measurement interval, $d t$.

b. Measure real power $\left(P_{1000}(t)\right)$ for the $1000 \mathrm{~kW}$ diesel generator for each measurement interval, $d t$.

c. Measure real power $\left(P_{900}(t)\right)$ for the $900 \mathrm{~kW}$ diesel generator for each measurement interval, $d t$.

d. Measure real power $\left(P_{\text {Solar }}(t)\right)$ for the solar array at Fort Carson for each measurement interval, $d t$. All individual inverters will be lumped into one term.

e. Accumulate the real power for each interval using equation (A.77):

$$
P_{\text {Gen }}(t)=P_{1250}(t)+P_{1000}(t)+P_{900}(t)+P_{\text {Solar }}(t)
$$

2) Find the maximum output value interval, $t_{\max }$, of $P_{G e n}(t)$.

3) Determine the reactive power for each generator on the microgrid at the peak demand time, $t_{\max }$.

a. Measure reactive power $\left(Q_{1250}\right)$ for the $1250 \mathrm{~kW}$ diesel generator at the peak demand time, $t_{\max }$.

b. Measure reactive power $\left(Q_{1000}\right)$ for the $1000 \mathrm{~kW}$ diesel generator at the peak demand time, $t_{\max }$.

c. Measure reactive power $\left(Q_{900}\right)$ for the $900 \mathrm{~kW}$ diesel generator at the peak demand time, $t_{\max }$.

d. Measure reactive power $\left(Q_{\text {Solar }}\right)$ for the solar array at the peak demand time, $t_{\max }$. All individual inverters will be lumped into one term.

4) Determine the reactive power for load sources on the microgrid at the peak demand time, $t_{\max }$.

5) Accumulate the load reactive power for $t_{\max }$.

6) Determine the reactive power loss percentage on the system during SPIDERS operation using equation (A.78):

$$
Q_{\text {LOSSPERCSPIDERS }}=\frac{\left(Q_{1250}+Q_{1000}+Q_{900}+Q_{\text {Solar }}\right)-Q_{L O A D M A X}}{\left(Q_{1250}+Q_{1000}+Q_{900}+Q_{\text {Solar }}\right)} \times 100
$$

7) Estimate the reactive losses during "normal' operations. 


\section{A.2.2 MOE 2.2: End-use Efficiency}

MOE 2.3 will focus on the efficiency of the end-use loads. Traditionally, this would be associated with methods like reducing system voltage as part of a Conservation Voltage Reduction (CVR) or Volt-var Optimization (VVO). However, these implementations are not explored in the SPIDERS project. This particular metric will qualitatively examine any benefits to operating the microgrid under SPIDERS compared to traditional modes. This could often be associated with better assumed power quality through the introduction of new reactive resources or devices.

\section{A.3 MOE 3: Renewables Integration}

MOE 3 will evaluate SPIDERS ability to use the available renewable generation sources during critical operations periods. This will primarily be achieved by quantifying the power and energy produced by the photovoltaic array. This information will provide an indication of the value of the renewable generation sources during the critical operations periods. The information may lead to better sizing estimates for future installations at the same base, as well as aid in the selection of the appropriate size of diesel generator.

For Phase 2 of the SPIDERS project, only photovoltaic array inputs are available for operation. Wind turbine capabilities may be added to the operational system at a later date, but will not be included in the Phase 2 OD. Electric vehicles are available on the system and may be used to mitigate the variability of the solar generation. For all calculations of MOE 3, EV contributions will be considered part of the generation pool.

\section{A.3.1 MOE 3.1: PV Penetration Level}

MOE 3.1 evaluates the contributions the photovoltaic generation provides during emergency operations. The information can serve as a means to determine a simple estimate of how much capacity the PV array can provide. The measures of effectiveness can also provide a very rough indication of sizing relationships for future PV deployments. Phase 2 testing is expected to evaluate the existing photovoltaic array, sized at $2.0 \mathrm{MW}$.

\section{A.3.1.1 MOP 3.1.1: PV Percent of Name Plate}

PV percent of name plate quantifies how much power the photovoltaic array is providing compared to its rated output. The output will be a function of the solar energy reaching the PV array and will be influenced by cloud cover and dirt on the array. The percentage will be calculated on the assumption the photovoltaic array is running 24-hours a day. The percentage calculated will represent an average value for the critical operations period. PV percent of name plate will be calculated as: 
1) Measure real power $(P(t))$ and reactive power $(Q(t))$ for the photovoltaic array for each measurement interval, $d t$.

2) Determine the magnitude of the apparent power using equation (A.79):

$$
|S(t)|=\sqrt{P(t)^{2}+Q(t)^{2}}
$$

3) Determine the PV percent of name place using equation (A.80):

$$
P V_{\text {\%onameplate }}=\frac{\frac{1}{T} \int_{t=0}^{T}|S(t)| d t}{S_{P V \text { rated }}} \times 100
$$

where $S_{P V r a t e d}$ is the nameplate rating of the PV array (2.0 MW for Phase 2).

\section{A.3.1.2 MOP 3.1.2: PV Percent of Peak Load}

PV percent of peak load quantifies how much power the photovoltaic array provides during the peak load period of the critical operations. The output of the PV generation is a function of the solar energy reaching the PV array and will be influenced by cloud cover and dirt on the array. Load power is influenced by demands of the system, so peak PV output and peak load demand are not expected to coincide. PV percent of peak load will be calculated as:

1) Determine the real power $\left(P_{G e n}(t)\right)$ for the generation sources on the microgrid for each measurement interval, $d t$, during SPIDERS operation.

a. Measure real power $\left(P_{1250}(t)\right)$ for the $1250 \mathrm{~kW}$ diesel generator for each measurement interval, $d t$.

b. Measure real power $\left(P_{1000}(t)\right)$ for the $1000 \mathrm{~kW}$ diesel generator for each measurement interval, $d t$.

c. Measure real power $\left(P_{900}(t)\right)$ for the $900 \mathrm{~kW}$ diesel generator for each measurement interval, $d t$.

d. Measure real power $\left(P_{\text {Solar }}(t)\right)$ for the solar array at Fort Carson for each measurement interval, $d t$. All individual inverters will be lumped into one term.

e. Measure real power $\left(P_{E V S E}(t)\right)$ for the electric vehicles for each measurement interval, $d t$. Note that EVs can both charge and discharge, so this value will retain the appropriate sign for inclusion in the full generator output, $P_{G e n}(t)$.

f. Accumulate the real power for each interval using equation (A.81):

$$
P_{\text {Gen }}(t)=P_{1250}(t)+P_{1000}(t)+P_{900}(t)+P_{\text {Solar }}(t)+P_{\text {EVSE }}(t)
$$

2) Determine the maximum output value of $P_{G e n}(t), t_{\max }$. 
3) Determine the reactive power output of each generator at time $t_{\max }$ :

a. Measure the reactive power output $\left(Q_{1250}\right)$ for the $1250 \mathrm{~kW}$ diesel generator at $t_{\max }$.

b. Measure the reactive power output $\left(Q_{1000}\right)$ for the $1000 \mathrm{~kW}$ diesel generator at $t_{\max }$.

c. Measure the reactive power output $\left(Q_{900}\right)$ for the $900 \mathrm{~kW}$ diesel generator at $t_{\max }$.

d. Measure the reactive power output $\left(Q_{\text {Solar }}\right)$ for solar array at Fort Carson at $t_{\max }$.

e. Measure the reactive power $\left(Q_{E V S E}\right)$ for the electric vehicles at $t_{\max }$.

4) Determine the apparent power for each generator on the microgrid at peak load interval, $t_{\max }$.

a. Calculate the apparent power for the $1250 \mathrm{~kW}$ diesel generator at $t_{\max }$ using equation (A.82):

$$
S_{1250}=\sqrt{\left(P_{1250}\left(t_{\max }\right)\right)^{2}+\left(Q_{1250}\right)^{2}}
$$

b. Calculate the apparent power for the $1000 \mathrm{~kW}$ diesel generator at $t_{\max }$ using equation (A.83):

$$
S_{1000}=\sqrt{\left(P_{1000}\left(t_{\max }\right)\right)^{2}+\left(Q_{1000}\right)^{2}}
$$

c. Calculate the apparent power for the $900 \mathrm{~kW}$ diesel generator at $t_{\max }$ using equation (A.84):

$$
S_{900}=\sqrt{\left(P_{900}\left(t_{\max }\right)\right)^{2}+\left(Q_{900}\right)^{2}}
$$

d. Calculate the apparent power for the solar array at Fort Carson at $t_{\max }$ using equation (A.85):

$$
S_{\text {Solar }}=\sqrt{\left(P_{\text {Solar }}\left(t_{\max }\right)\right)^{2}+\left(Q_{\text {Solar }}\right)^{2}}
$$

e. Calculate the apparent power for the EVSE at $t_{\max }$ using equation (A.86). The EVSE value will be assigned an appropriate sign (- for charging, + for discharging), dependent on its state during $t_{\max }$.

$$
S_{E V S E}=\sqrt{\left(P_{E V S E}\left(t_{\max }\right)\right)^{2}+\left(Q_{E V S E}\right)^{2}}
$$


5) Compute the PV percent of peak load using equation (A.87):

$$
P V_{\%_{\text {p peakload }}}=\frac{S_{\text {Solar }}}{S_{1250}+S_{1000}+S_{900}+S_{\text {Solar }}+S_{\text {EVSE }}} \times 100
$$

\section{A.3.1.3 MOP 3.1.3: PV Percent of Energy Supplied}

$\mathrm{PV}$ percent of energy supplied quantifies how much energy the photovoltaic array provides to the system compared to all the other sources of energy on the system. This determines how much of a contribution the PV array makes to maintaining the energy requirements during the SPIDERS operation interval. PV percent of energy supplied will be calculated as:

1) Measure the apparent power for all of the generators on the microgrid during SPIDERS operation:

a. Calculate the apparent power for the $1250 \mathrm{~kW}$ diesel generator for each measurement interval, $d t$, using real power measurements $\left(P_{1250}(t)\right)$ and reactive power measurements $\left(Q_{1250}(t)\right)$ for each measurement interval, $d t$, using equation (A.88):

$$
S_{1250}(t)=\sqrt{\left(P_{1250}(t)\right)^{2}+\left(Q_{1250}(t)\right)^{2}}
$$

b. Calculate the apparent power for the $1000 \mathrm{~kW}$ diesel generator for each measurement interval, $d t$, using real power measurements $\left(P_{1000}(t)\right)$ and reactive power measurements $\left(Q_{1000}(t)\right)$ for each measurement interval, $d t$, using equation (A.97):

$$
S_{1000}(t)=\sqrt{\left(P_{1000}(t)\right)^{2}+\left(Q_{1000}(t)\right)^{2}}
$$

c. Calculate the apparent power for the $900 \mathrm{~kW}$ diesel generator for each measurement interval, $d t$, using real power measurements $\left(P_{900}(t)\right)$ and reactive power measurements $\left(Q_{900}(t)\right)$ for each measurement interval, $d t$, using equation (A.98):

$$
S_{900}(t)=\sqrt{\left(P_{900}(t)\right)^{2}+\left(Q_{900}(t)\right)^{2}}
$$

d. Calculate the apparent power for the solar array at Fort Carson for each measurement interval, $d t$, using real power measurements $\left(P_{\text {Solar }}(t)\right)$ and reactive power measurements $\left(Q_{\text {Solar }}(t)\right)$ for each measurement interval, $d t$, using equation (A.99):

$$
S_{\text {Solar }}(t)=\sqrt{\left(P_{\text {Solar }}(t)\right)^{2}+\left(Q_{\text {Solar }}(t)\right)^{2}}
$$


e. Calculate the apparent power for the EVSE for each measurement interval, $d t$, using real power measurements $\left(P_{E V S E}(t)\right)$ and reactive power measurements $\left(Q_{E V S E}(t)\right)$ for each measurement interval, $d t$, using equation (A.89). As with previous usages of apparent power on the EVSE point, periods of charge will be assigned negative values and periods of discharge will be assigned positive values:

$$
S_{E V S E}(t)=\sqrt{\left(P_{E V S E}(t)\right)^{2}+\left(Q_{E V S E}(t)\right)^{2}}
$$

2) Compute total energy produced during the SPIDERS microgrid operation period using equation (A.101):

$$
E_{\text {SPIDERS }}=\int\left(S_{1250}(t)+S_{1000}(t)+S_{900}(t)+S_{\text {Solar }}(t)+S_{\text {EVSE }}(t)\right) d t
$$

3) Compute the total energy produced by the photovoltaic array during the SPIDERS operation time using equation (A.102):

$$
E_{\text {Solar }}=\int S_{\text {Solar }}(t) d t
$$

4) Determine the PV percent of energy supplied using equation (A.103):

$$
E_{\% P V}=\frac{E_{\text {Solar }}}{E_{\text {SPIDERS }}} \times 100
$$

\section{A.3.1.4 MOP 3.1.4: PV Capacity Factor}

PV capacity factor quantifies the relationship between the ideal energy output of the photovoltaic array and how much energy was actually produced. If a generator was producing $100 \%$ of the name plate capacity for a full year, its capacity factor would be $100 \%$. Since the generator may not be operating at peak output, or may not be generating at all times of the day, this value is below $100 \%$ for most generators. The value will assume a PV unit is available to operate all hours of the day and not prorated for daylight hours only. The capacity factor is typically computed over a year-long interval, but will only be computed over the interval defined by the SPIDERS mode of operation. The PV capacity factor will be calculated as:

1) Measure real power $(P(t))$ and reactive power $(Q(t))$ produced by the photovoltaic array for each measurement interval, $d t$.

2) Determine the magnitude of the apparent power using equation (A.104):

$$
|S(t)|=\sqrt{P(t)^{2}+Q(t)^{2}}
$$


3) Determine the amount of energy generated using equation (A.105):

$$
E_{G E N}=\int_{t=0}^{T}|S(t)| d t
$$

where $t=0$ to $T$ represents the time interval of the SPIDERS operation.

4) Estimate the PV capacity factor using equation (A.106):

$$
\text { PV Capacity Factor }=\frac{E_{G E N}}{S_{\text {nameplate }} T^{T}} \times 100
$$

where $S_{\text {nameplate }}$ is the rated power output of the PV system (2.0 MW for Phase 2).

\section{A.4 MOE 4: Suitability}

Operational suitability is the degree to which a system can be satisfactorily placed in field use. Because many of the traditional suitability criteria apply to full-scale acquisition systems, we will focus the SPIDERS suitability criteria on a set of elements designed to assess the degree to which the technical demonstration system can be embedded in ongoing base grid operations to test operational scenarios, and the potential for incorporation into ongoing operations to reduce utility power usage.

The principal consideration for suitability is that new equipment enhances the operation according to the objectives of the JCTD implementation directive, without putting undue burden on existing systems of equipment, personnel and procedures, and doing so in a safe and reliable manner. In practice, this means that the SPIDERS enabled facilities will be able to perform normally, and that existing personnel can incorporate any procedural changes within their current work processes. The nature of many suitability criteria is qualitative, and will require interviews with personnel prior to, during and after the OD. There are other parameters than can be collected through equipment logs, checklists, questionnaires, and evaluator inspection of system components.

\section{A.4.1 MOE 4.1: Training Requirements and Material}

Because SPIDERS is a developmental/demonstration system, a full-scale training plan is not expected or necessary. However, it will be necessary to train relevant DPW, operations and maintenance contractor personnel, and facility personnel regarding the relatively few functions they will need to carry out during the operational demonstration.

Aggregation of the two training requirements and material MOPs into a suitability MOE element will consist of a narrative description of our findings for the MOPs, discussing aspects of the training process that are positive, and those areas that may require further development to ensure 
that personnel are adequately trained. This narrative may also include discussion of anticipated training needs for post-demonstration incorporation of SPIDERS into ongoing base operations.

\section{A.4.1.1 MOP 4.1.1: User Training Needs Identified}

User training needs identified can be addressed by interviews with the system integrator, DPW, operations and maintenance contractor staff, and facility managers and personnel regarding their expected task requirements for SPIDERS operation. We will review the integrator process and results for documenting training needs, which would comprise a basic job-task analysis and training needs statement for the tasks. The review will consider how well the range of personnel and responsibilities have been linked to specific training requirements, and post-demonstration feedback on areas where training may be enhanced or modified.

\section{A.4.1.2 MOP 4.1.2: Training Material Developed}

Training material developed, will consist of a review of the presentation and documentation material prepared by the integrator to fulfill the training needs identified by their needs assessment. Specific areas of evaluation will include comprehensiveness (i.e., is there training material that addresses each personnel position and need identified?), accessibility (i.e., is the material available in a form that can be easily accessed by trainees for reference?), visual/verbal clarity, accuracy and timeliness (i.e., has the material been presented to relevant personnel in sufficient time to permit questions and practice (if necessary) of the action sequences in SPIDERS operation?).

Reviews of the task requirements and training needs for SPIDERS can be accomplished in advance of the operational demonstration through teleconferences and document exchange. Any training will need to be observed by the evaluator, most probably in the pre-demonstration period of developmental testing.

\section{A.4.2 MOE 4.2: Safety}

Safety is a critical concern for any electrical system, and SPIDERS operation is no exception. There are two MOPs for safety:

\section{A.4.2.1 MOP 4.2.1: Establishment of Safety Procedures}

In order to evaluate if proper safety procedures have been established the assessment team will interview DPW, operations and maintenance contractor managers, facility managers and the system integrator to document and compare current safety-related Standard Operating Procedures (SOPs) with SPIDERS safety-related SOPs. This information will also be utilized to verify that SPIDERS specific safety training was performed by the same methods documented in MOP 4.1.2. 


\section{A.4.2.2 MOP 4.2.2: Procedures for Operational Modes}

Special attention will be paid to identifying what, if any, modes of SPIDERS require special communication to DPW and operations and maintenance contractor personnel regarding SPIDERS status (e.g. radio communication, lock out tag out). These communications will be documented during observation of the demonstration.

\section{A.4.3 MOE 4.3: Human Factors}

Human Factors measures of performance cover a range of system and end user issues comprising effective human-system integration. The focus of most of the measurements in the human factors area is qualitative, i.e., precise instrumented data are not available, with the exception of alarm logs and facility process variables. The assessment and combination of the component MOPs is thus a matter of system engineering judgment concerning the extent to which the MOPs reflect acceptable system performance, or the extent to which design modifications can overcome deficiencies identified during the demonstration. Within MOE 4.3 there are 4 specific MOPs.

\section{A.4.3.1 MOP 4.3.1: Unobtrusive Operation}

The first MOP for MOE 4.3 is to ensure the unobtrusiveness of SPIDERS modes at designated facilities. The rationale for this measure is a lesson learned from pervious SPIDERS deployment, where personnel at SPIDERS enabled facilities did not want to be involved in electrical grid diagnosis, or microgrid operation. Their concern is that the backup power be engaged with minimal disruption to their operation, and that the facility processes are maintained within established limits. These criteria can be evaluated both through quantitative means, such as equipment logs, and through qualitative means such as interviews and debriefings following the demonstration. To the extent that facility operations proceed as they normally would in a power outage, this MOP would be rated as successful. Should the operation of SPIDERS introduce anomalous equipment trips or otherwise be associated with facility processes falling outside of their established bounds, the MOP would be rated as unsuccessful.

\section{A.4.3.2 MOP 4.3.2: Situational Awareness for DPW}

Situational awareness for DPW will be addressed prior to the operational demonstration by interviewing DPW personnel regarding the operational sequences to be carried out for SPIDERS activation, and during the demonstration by observation of these sequences. This will include exercise of the decision hierarchy for activating SPIDERS, i.e., communicating with relevant DPW and Fort Carson personnel to reach a decision to activate SPIDERS mode. Further inputs for this MOP will be obtained by reviewing the SPIDERS alarm logs to determine the temporal relationship of alarms at the DPW Human machine Interface (HMI) to the power outage, and interviews with the operators concerning the alerting and diagnostic aspects of the alarms. 


\section{A.4.3.3 MOP 4.3.3: HMI Interactions}

MOP 4.3.3 HMI Interactions, will be addressed before and during the demonstration by inspection of the graphical interface provided at the DPW HMI. The various mode transitions and alarm states will be listed and illustrated by the integrator during developmental testing, and will be assessed in terms of ease-of-use.

\section{A.4.3.4 MOP 4.3.4: Decision Support}

MOP 4.3.4 will be assessed during developmental testing, and is meant to provide a means whereby operators are guided to what error states exist, and how to correct those errors. This area will need further definition through interaction with the integrator and DPW during the technical demonstration.

Aggregation of the Human Factors MOPs into a suitability MOE element will consist of a narrative description of our findings for the MOPs, discussing aspects of the developmental and operational demonstration testing that illustrate performance and potential design enhancements of the SPIDERS HMI.

\section{A.4.4 MOE 4.4: Maintainability}

Maintainability deals with the ability for the SPIDERS system to be operated and sustained through its useful life. As any empirical evidence of the long-term maintainability of the system is outside the scope of the test and evaluation of SPIDERS, this issue will be addressed by examining that the foundation for such maintainability. This foundation comprises the following elements: that SPIDERS components have appropriate access availability and restrictions associated with both hardware and software (MOP 4.4.1), that system procedures are available to understand how and when to maintain the system (MOP 4.4.2), and that resources for properly maintaining the system are available and accessible for maintenance (related to manpower supportability).

\section{A.4.4.1 MOP 4.4.1: User Access}

MOP 4.4.1 will utilize a qualitative evaluation of both interviews of appropriate DPW staff and review of any protocols and procedures supplied by the integrator and/or implemented by DPW. By examining access as a component of maintainability it will be possible to evaluate if the capability of qualified personnel to access SPIDERS components in order to maintain, update, and sustain the system, as well as determining if personnel without proper SPIDERS training could access and potentially harm the SPIDERS system or SPIDERS enabling components. 


\section{A.4.4.2 MOP 4.4.2: System Update Procedures}

MOP 4.4.2 will also be evaluated in a qualitative fashion by examining integrator supplied materials associated with maintenance intervals, maintenance schedule, procedures for updating and/or replacing software and hardware components, and system testing protocols.

\section{A.4.4.3 MOP 4.4.3: Component Availability}

MOP 4.4.3 will utilize interviews with both the integrator and DPW personnel to determine if the procedures and availability of various system components matches with the DPW requirements for component availability, on-site spares and system downtime.

\section{A.4.5 MOE 4.5: Manpower Supportability}

The supportability MOPs address the need for appropriate personnel to operate and service a system that is incorporated for routine operation. Although this is not clearly within the scope of the SPIDERS operational demonstration, the developmental and operational testing may provide an opportunity to address this issue.

\section{A.4.5.1 MOP 4.5.1: Post OD Operations}

MOP 4.5.1 will determine whether base decision makers have determined if SPIDERS will be utilized on a routine basis for offsetting demand power purchase charges. If there is a desire to do this, then a plan for how and when SPIDERS will be used is essential, and interviews with relevant personnel will determine the status of this plan.

\section{A.5 MOE 5: Cyber Security}

One of the primary goals of the SPIDERS project is to demonstrate a microgrid that is robust even in the face of cyber or combined cyber-physical attacks. The effectiveness of the cyber security defenses built into the SPIDERS project must be evaluated according to the following:

1) Evaluate understanding of SPIDERS system environment. The cyber security architecture and design relies heavily on the understanding of the SPIDERS system environment. The system environment includes items such as the installation site(s), the physical dependencies between the installation site(s), any control and information technology (IT) dependencies, etc.

2) Evaluate understanding of SPIDERS system components. As part of the cyber security architecture and design, all system components must be clearly identified. All communication paths plus all protocols used for either IT or control systems must be identified and listed. The design must also identify all auxiliary systems such as systems used to store data, software and firmware patches, system design drawings, etc. Auxiliary protocols such as Domain Name System (DNS) or Network Time Protocol (NTP) must be identified. 
3) Evaluate understanding of SPIDERS cyber security operational and functional requirements. The effectiveness of the SPIDERS cyber security architecture and design can only be evaluated against the requirements. In this case, SPIDERS requirements will come from two established standards: DoD 8500.2 and NIST SP 800-82.

4) Evaluate completeness of SPIDERS cyber security architecture and design in meeting the requirements stated in (3). The SPIDERS cyber security architecture and design must be evaluated to determine how well it meets the cyber security functional and operational requirements. This activity is both a "paper" activity and a laboratory testing activity that results in a report of how well the cyber security policies and controls meet the SPIDERS requirements.

5) Evaluate the cyber and physical security of the SPIDERS design by testing in the operational infrastructure setting. Once the SPIDERS system is deployed, the cyber security team will conduct testing to ensure that systems are operating nominally (according to SPIDERS cyber security architecture and design) and that no errors in configuration or operation exist.

6) Reconcile results from (4) and (5) with (1), (2), and (3). Feedback from the reconciliation is given to the SPIDERS cyber security team.

7) Re-evaluate the assessment based on findings from (6). If any shortcomings are found in (6), then the assessment design will be modified to address the shortcoming or the requirement will be changed.

As can be seen from the steps described above, the cyber security evaluation process is iterative.

\section{A.5.1 MOE 5.1: CSET Evaluation}

By comparing CSET evaluation results from Phase 1 and Phase 2, year over year improvements can be identified. In addition, CSET findings will indicate where improvements are required or no changes have occurred.

\section{A.5.2 MOE 5.2: Static Code Evaluation}

The static code evaluation is a new Phase 2 effort. As such a comparison to Phase 1 results is not possible. A goal of the assessment team is to increase the evaluation rigor year over year, which is accomplished, in part, by the addition of the static code analysis. Static code analysis cannot prove that a set of code is free from cyber security issues, especially since many cyber security issues only occur at run time. However, code analysis can quickly identify several common security issues (e.g., buffer overflows and missing user input validation). Results from Phase 2 will be used as a baseline for comparison with the Phase 3 static code analysis results.

\section{A.5.3 MOE 5.3: Red Team Assessment}

As with the CSET Evaluation, Red Team assessment results from Phase 1 and Phase 2 will be compared to identify year over year improvements. The intent is also to evaluate the 
effectiveness of the iterative analysis approach by examining the effectiveness of the Phase 2 Red Team activities. New during Phase 2 is the passive analysis of the operational microgrid during the Red Team activity. Coordination between the Red Team and PNNL is required to accurately measure the impact of Red Team activities upon the operational environment.

\section{A.6 MOE 6: Economics}

For the Phase 2 OD it was decided by the IMT to not include MOE 6. This decision was primarily driven by the fact that the Phase 2 version of SPIDERS will not operate in a grid connected mode for prolonged period of time. 


\section{Appendix B: Phase 2 OD Operational Procedure and Responses to Abnormal Conditions}

This appendix gives a broad outline for Operational Procedure (OP) 1, the execution of the Phase 1 OD. In addition to OP-1 a number of Casualty Procedure (CPs) are provided. Both the OP and CPs apply to the execution of the OD, and are not general procedures for the normal operation of SPIDERS.

\section{B.1 Operational Procedure 1}

OP-1 is the procedure by which the OD is conducted. This procedure gives general guidance and is not intended to cover all required actions. OP-1 is a separate document from the IAP.

\section{B.1.1 Stage 0: Cyber Evaluation}

This is a non-operational evaluation of SPIDERS cyber security as determined by a Cyber Security Evaluation Tool (CSET) evaluation. CSET will be used to determine SPIDERS compliance with DoD 8500.2 and NIST SP800-82. The CSET evaluation will be conducted either prior to the OD or in parallel with the operational stages. The cyber evaluation will be mostly complete prior to the OD, only verification and final confirmation of facts will be conducted.

\section{B.1.2 Stage 1: Separation from CSU System}

This stage begins with the SPIDERS facilities being in a normal configuration with power supplied from the CSU system. The solar PV and EVs may or may not be in operation, but the diesel generators are not in operation. The first stage commences when the manual command to transition to independent islanded operations is given. This stage is completed as soon as interconnected operations are terminated, and a stable operating island is formed. A stable operating island is defined as operations independent of the CSU system with power provided by a backup diesel generator and solar PV, possibly with the EVs and EVSE in operation. Both voltage and frequency must be stable about nominal operating values.

\section{B.1.3 Stage 2: Islanded Operations}

This stage begins after the successful separation from utility supplied electricity and the formation of a stable island. The ability of SPIDERS to manage the operation of variable output renewable resources and to reduce primary fuel consumption while supplying the critical load is the primary focus of this Stage. This stage is completed when the manual command to reconnect to the CSU system is given. 


\section{B.1.4 Stage 3: Reconnecting with the CSU System}

This stage begins with the completion of the 80 hour test period of Stage 2, with the system still operating as a stable island, and the command to reconnect to the utility system has been given. This stage will examine the ability of SPIDERS to seamlessly interconnect with utility system.

\section{B.2 Casualty Procedures}

The following casualty procedures give limited guidance for how conduct the OD during abnormal operations.

\section{B.2.1 CP-1: SPIDERS Does not Successfully Island}

In the event that the SPIDERS system fails to successfully island, it will be returned to normal grid connected operation and a second attempt will be made. Up to three attempts may be made before the OD is considered an interim failure. If the system fails to successfully island initially, but does on the second or third attempt, the event will be noted and the OD can continue with the approval of the OTA, integrator, and system operators.

In the event that that the system fails to start after three attempts and the OD is considered an interim failure, the remainder of the OD time will be used to trouble shoot the problem and determine if it can be corrected. If the problem is corrected in a timely manner, it will be up to the OTA to determine if the OD can continue in the remaining time, or if the interim failure becomes an OD failure.

\section{B.2.2 CP-2: Failure of Major Electrical Component During OP-1}

It is conceivable that during the OD there could be a failure of a major electrical component such as a transformer or underground cable. If there is a protective action in the SPIDERS portion of the Fort Carson electrical infrastructure, regardless of the cause, the OD can be paused or halted at the discretion of the system operators or the OTA. Under no circumstances will the OD be allowed to continue under unsafe conditions.

\section{B.2.3 CP-3: SPIDERS Fails to Successfully Synchronize with CSU System}

In the event that the SPIDERS system fails to successfully reconnect to the CSU system, up to two additional attempts can be made. If the system fails to reconnect three times, the reconnection phase will be considered unsatisfactory. If the system fails to reconnect initially, but does on the second or third attempt, the event will be noted and the OD can continue with the approval of the OTA, integrator, and system operators, similar to CP-1. 


\section{B.2.4 CP-4: Abnormal Weather Event}

Under severe or abnormal weather conditions the OD can be suspended and rescheduled for a later date. This requires a strong justification principally involving the safety of personnel. To re schedule the OD due to weather related events requires the agreement of the OTA and the IMT, including the OE.

\section{B.2.5 CP-5: Failure of Data Collection System}

If the data collection system should experience a failure during the OD, the extent of the failure will have to be determined. For a partial loss of data collation ability the OD may continue at the OTAs discretion, with concurrence from the OM. If a complete failure of the data collection system occurs, then the OD will have to be rescheduled. 



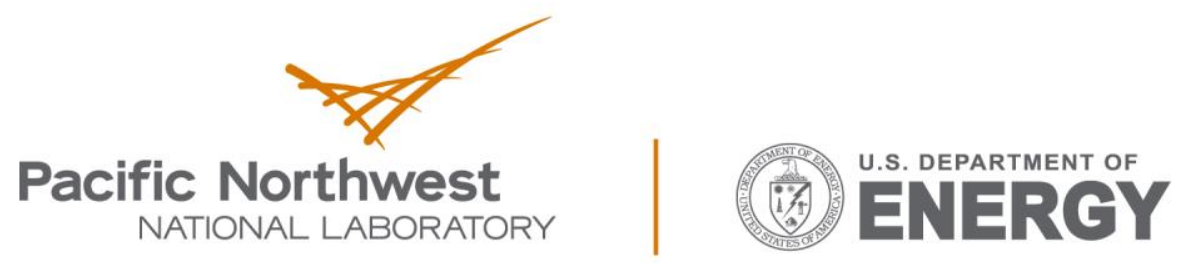

Proudly Operated by Battelle Since 1965

902 Battelle Boulevard

P.O. Box 999

Richland, WA 99352

1-888-375-PNNL (7665)

www.pnnl.gov 